\title{
GRAPHENE and DERIVATIVES - SYNTHESIS TECHNIQUES, PROPERTIES AND THEIR ENERGY APPLICATIONS
}

\author{
Bhagya Lakshmi Dasari ${ }^{1}$, Jamshid M Nouri ${ }^{1}$, Dermot Brabazon² and Sumsun Naher ${ }^{1}$ * \\ ${ }^{1}$ Department of Mechanical Engineering and Aeronautics, City, University of London, London, UK \\ ${ }^{2}$ Advanced Processing Technology Research Centre, School of Mechanical and Manufacturing Engineering, \\ Dublin City University, Dublin, Ireland
}

\begin{abstract}
2D nanomaterials with exceptional electrical, mechanical and thermal properties are promising reinforcing materials for fabricating high-performance composite materials. Rapid developments in nanotechnology in recent years have facilitated the development of advanced materials for functional devices. In particular, this review is focussed on the application of graphene nanoparticle-based composites (GNP's) and graphene derivatives in the fields of energy storage and conversion devices. This review focuses on these recent developments including the synthesis of graphene-based materials and its derivative, as well as the related achieved electrical, mechanical and thermal properties.
\end{abstract}

Keywords: Graphene oxide (GO), reduced graphene oxide (rGO), nanoparticles $(N P)$ and graphene nanoparticles (GNP).

\section{INTRODUCTION}

Graphene is a monolayer of carbon atoms that are arranged in a 2D honeycomb lattice with the C-C bond length of $0.142 \mathrm{~nm}$. Graphene is considered as a wonder material due to its impressive physical properties, such as high electron mobility of $250,000 \mathrm{~cm}^{2} / \mathrm{Vs}$ [1], high thermal conductivity of 5000 $\mathrm{W} / \mathrm{m}-\mathrm{K}$ [2] and exceptional Young's modulus of $1 \mathrm{TPa}$ [3]. Due to these amazing properties, graphene is given a special attention by researchers and has opened a new path for materials research. Graphene has been used in gas detection, composites, energy storage devices [4-7] and transistors [8]. Fig. 1 shows the industrial oriented applications of graphene, where energy-related applications and electronic applications occupy the highest percentages, whereas composites represent $11 \%$ of application usages [9]. The importance of composites is evident from the increase in the number of graphene publications related to energy applications from the Energy journal, shown in Fig. 2. There is no doubt that graphene possesses the potential to replace conventional materials in many practical applications. This review article provides a brief overview of the synthesis of graphene and its derivatives; their unique properties including electrical, mechanical and thermal; as well as their potential for energy storage and conversion applications. This review is followed by a discussion which summarises these activities and future potential applications. 


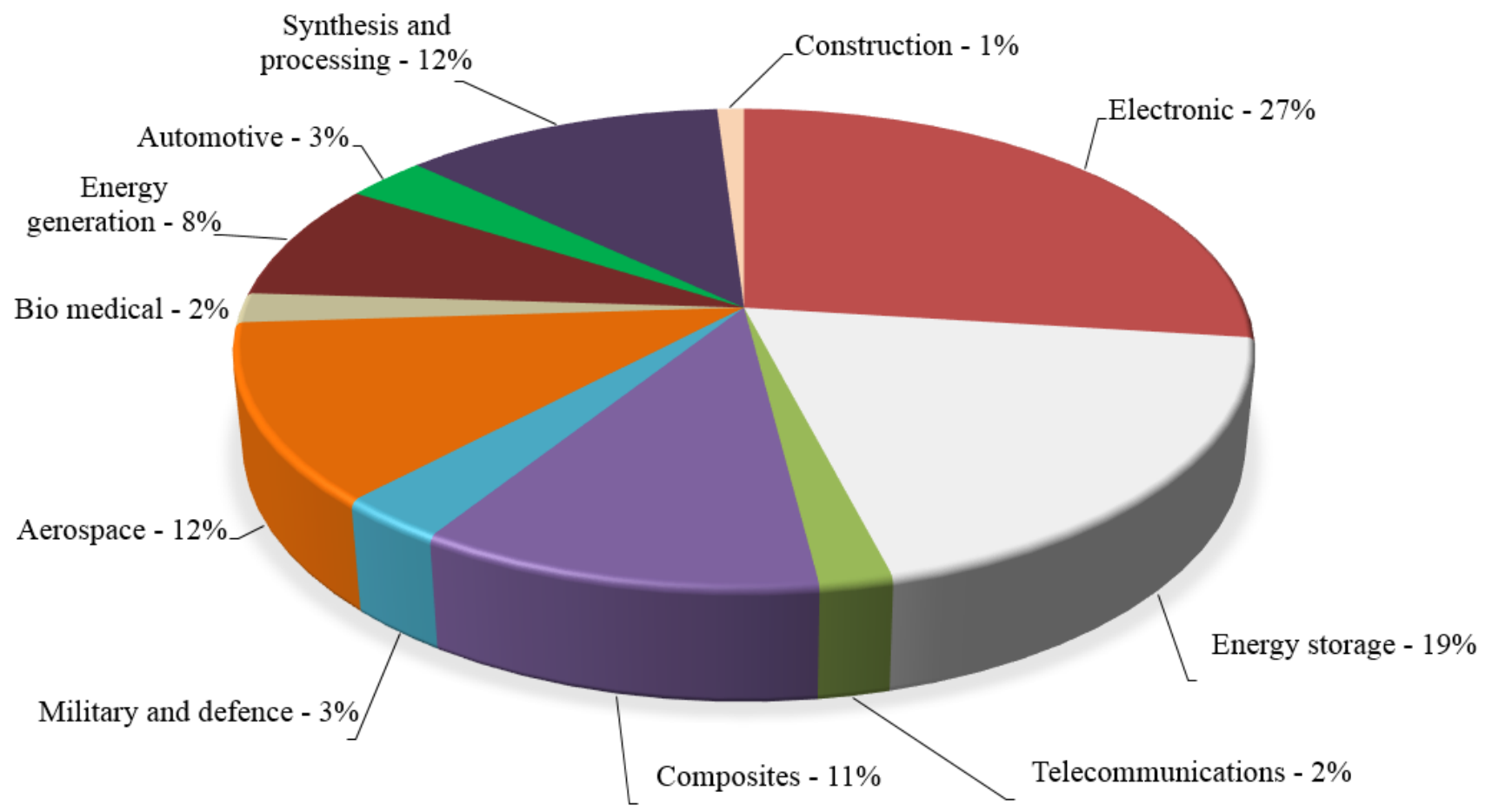

Figure 1: Industrial applications of graphene-based materials [9].

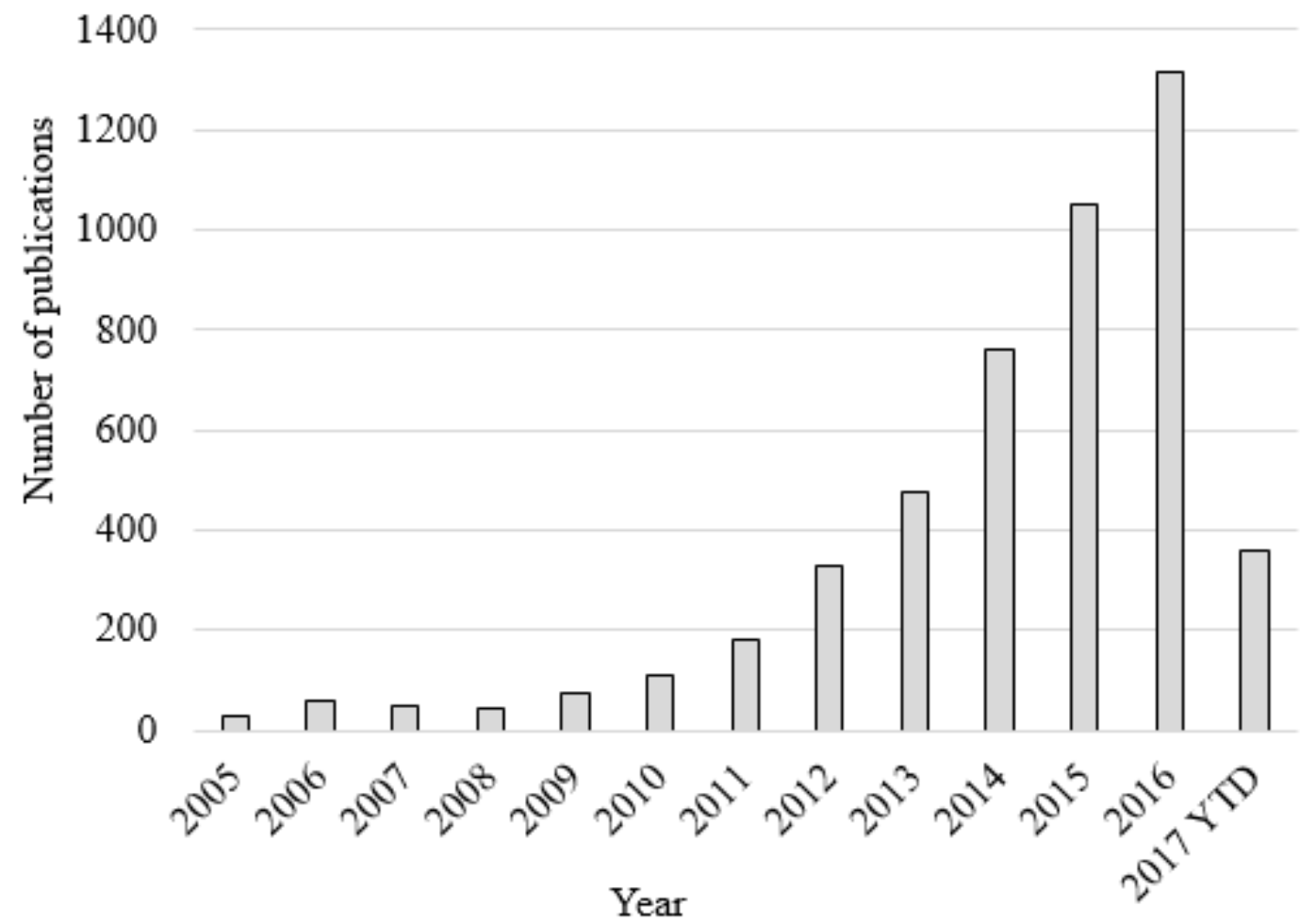

Figure 2: Number of graphene publications related to the field of energy research, Source: Web of Science. 


\section{SYNTHESIS OF GRAPHENE AND ITS DERIVATIVES}

\subsection{Graphene}

\subsubsection{Exfoliation of graphene and graphene nanosheets (GNS)}

Mechanical exfoliation was the initial technique used to synthesise graphene, this method was first developed in the lab by noble prize winners Andre Giem and Konstantin Novoselov [10]. This method involves the peeling off of layers of highly oriented pyrolytic graphite sheet. Figure 3 shows a pictorial representation of the exfoliation of graphene sheets using the scotch tape method, where graphite is placed on a substrate and repeatedly peeled using adhesive tape until monolayer sheet is obtained. Even though this process facilitates the production of a large amount of graphite oxide monolayer, Raman spectroscopy data have shown the existence of structural defects [11], these defects can in turn negatively affect the electrical conductivity due to the disruption of the electronic structure. Becerril et al. [12] have reported X-ray photoelectron spectroscopy (XPS) results that demonstrated that it is impossible to restore the structure of graphene after the thermal reduction of graphite oxide layers obtained by exfoliation. It is also possible to obtain a defect-free monolayer graphene by exfoliating graphite in $\mathrm{N}$-methyl-pyrrolidone however, this process is not recommended due to the high cost and high boiling point of the solvent [13].
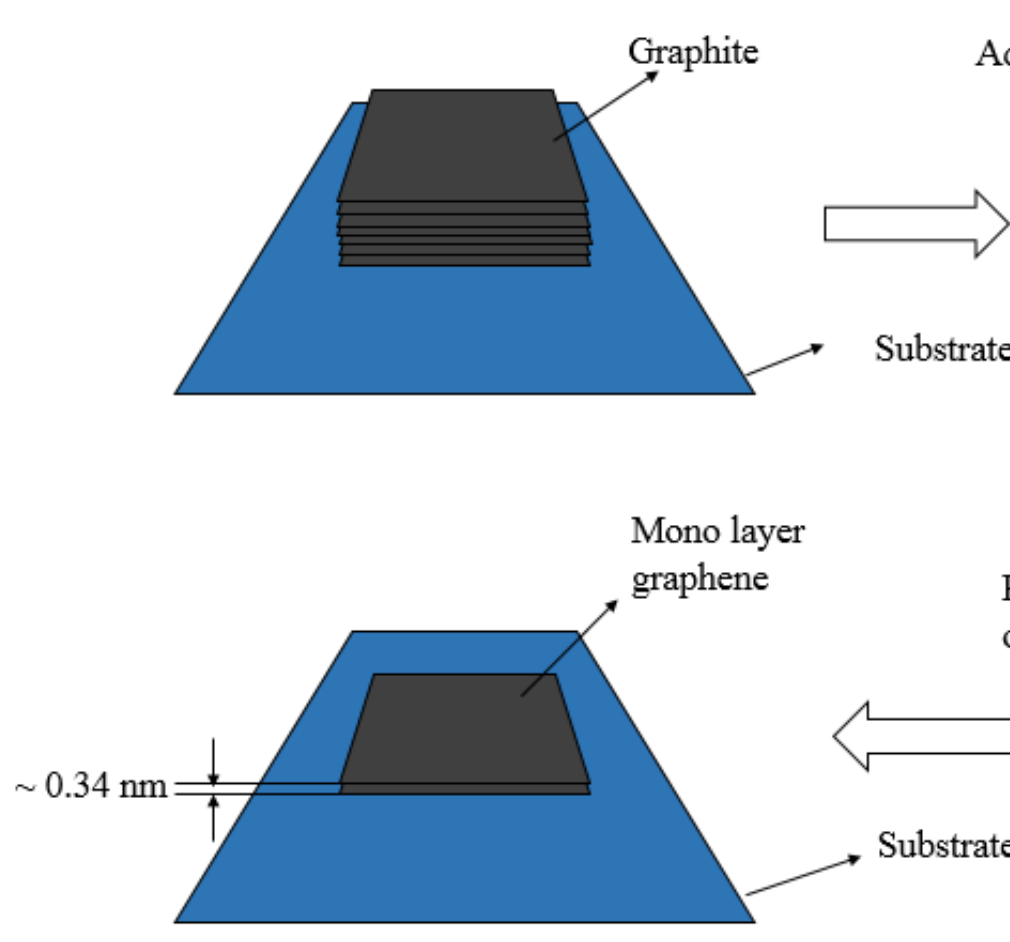

Adhesive tape

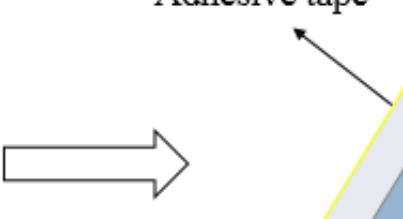

Substrate
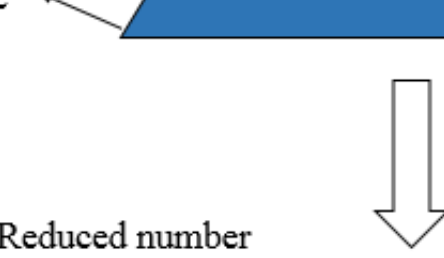
of layers

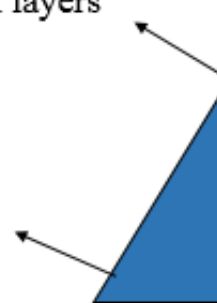

Figure 3: Schematic representation of sequential steps followed to exfoliate graphene layers using the scotch tape method. 
Graphite intercalation compounds (GIC's) or expandable graphite (EG) are graphene layers that incorporate small molecules between its layers to reduce agglomeration but the conductivity is reduced due to the disruption of the $\mathrm{sp}^{2}$ structure. The EG can be synthesised either by oxidation [14] or electrochemically in intercalating acid [15]. The parameters of ultrasonic solvent, ultrasonic time and ultrasonic power effects the volume of the expandable graphite. Due to the thermal expansion of the gases that are trapped in between the graphene sheets, EG can be easily expanded to 100 times in volume at high temperature [16]. Zhuang et al. [17] have reported the use of Fe as reducing agent to obtain GNS from exfoliated graphite. This method proved to be an eco-friendly route to produce GNS as this avoids the use of poisonous gases like hydrazine and hydroquinone. A new method to produce GNS of high quality was reported by Lei at al. [18], this includes a shear assisted supercritical $\mathrm{CO}_{2}$ exfoliation which is accelerated by high temperature and the high rotation speed of the $\mathrm{CO}_{2}$ fluid. The application of shear stress to the $\mathrm{CO}_{2}$ fluid helps to expand the graphite powders to GNS.

\subsubsection{Chemical vapour deposition of monolayer and multi-layer GNS}

Chemical vapour deposition (CVD) is one of the most promising techniques to produce monolayers of graphene sheets on a large scale. Somani et al. have successfully fabricated few layer graphene (FLG) through CVD, by using camphor as the precursor on $\mathrm{Ni}$ [19]. This has opened a new path to researchers to address controlling the number of layers, and to control the thickness on various metal substrates [20e26]. Bae et al. have reported the synthesis of 30-inch wide graphene films through CVD. Their process includes adhesion and etching followed by transfer of layers to the substrate [27]. The schematic representation of the sequential steps followed during the process is shown in Fig. 4 [27]. It is also noted that the produced graphene films have shown half-integer quantum Hall effect which indicates the high-quality graphene monolayers. A four-layer film with layer-by-layer doping has shown $\sim 90 \%$ transparency. It can be noted that the graphene layers synthesised by this method possess a potential to replace commercially available transparent electrodes. The possibility of substitutional doping by the introduction of other gases, e.g. $\mathrm{NH}_{3}$ during growth, is one interesting feature of the CVD approach [24]. Qu et al. have demonstrated the application of nitrogen doped graphene for the reduction of oxygen in fuel cells and it can be noted from the results that $\mathrm{N}$-graphene electrode displayed catalytic current of $\sim 3$ times higher than that of the $\mathrm{Pt} / \mathrm{C}$ electrode [28]. It can also be noted that $\mathrm{N}$-graphene electrode facilitates long-term stability and Poisson's effect over the Pt/C electrode during oxygen reduction in alkaline electrolytic solutions. The potential application of Ngraphene in lithium-ion batteries has also been reported, as this has a notable reverse discharge potential ( 2 times of pristine graphene) due to surface defects induced by nitrogen doping [29]. 

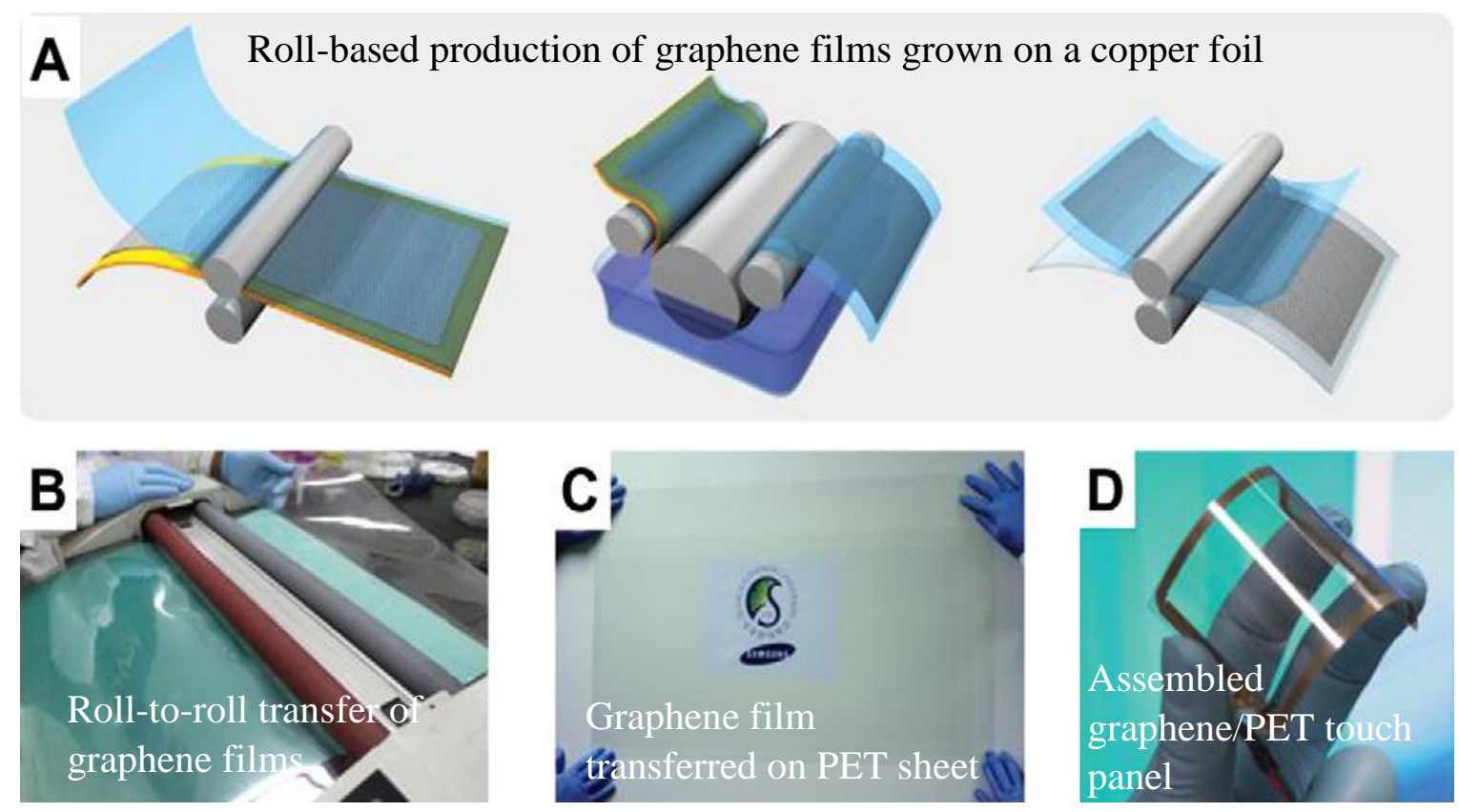

Figure 4: Sequential steps followed during film transfer of graphene films produced via the CVD approach [28].

Graphene can also be synthesised at low temperatures than the thermal CVD process of $1000^{\circ} \mathrm{C}$, by a technique known as plasma enhanced chemical vapour deposition (PECVD). This technique was first developed in 2004 using a gas mixture of $5-100 \% \mathrm{CH}_{4}$ in $\mathrm{H}_{2}$ at the power of $900 \mathrm{~W}$ and the substrate temperature at $680^{\circ} \mathrm{C}$ to produce mono and few-layer graphene sheets [30,31]. The major advantage of the PECVD technique is a lower deposition time of $\sim 5 \mathrm{~min}$ and a lower growth temperature compared to the conventional CVD process. Researchers have reported a new method of producing graphene using ultra high vacuum (UHV) annealing of $\mathrm{SiC}$ which proved to be beneficial in the semiconductor industry due to the advantage of obtaining the products on the surface of SiC [32-34]. The mechanism of UHV annealing of SiC involves heating the SiC substrate under $\mathrm{UHV}$, to sublimate the silicon atoms from the substrate, this leads to the re-arrangement of graphene layers with surface carbon atoms. The annealing time strongly influences the thickness of the obtained graphene layers. Tedesco et al. [35] and Emstev et al. [36] have reported the production of few-layer graphene (FLG) sheets with improved thickness and homogeneity at higher temperatures, $\sim 400^{\circ} \mathrm{C}$ above the UHV temperature. Even though the results obtained have in terms of homogeneity are promising, the challenging aspects of using this method for industrial applications is the control of the thickness of graphene layers and the epitaxial growth patterns of different $\mathrm{SiC}$ polar face. This method also lacks in addressing the issue of the existence of interface layer in between graphene, substrate and its effect on properties of the end product. A similar technique can be applied to grow graphene layers on metallic substrates. Porga et al. [37] and Sutler et al. [38] have reported the synthesis of epitaxial graphene sheets on ruthenium (Ru) crystals under UHV. A strong bonding of the first layer of graphene sheets with Ru substrate was 
reported. Whereas the second layer did not interact with the substrate and demonstrated a similar electronic structure as that of the free-standing graphene.

\subsubsection{Organic synthesis of graphene nanoribbons (GNR)}

Another method of producing the graphene is an organic synthesis that produces graphene-like poly acyclic hydrocarbons (PAHs). This method possesses the advantage of the versatility of synthesis, the capability to modify solubility. The major challenge during this process is preserving the dispersibility and plane geometry of the produced PAHs. A group of researchers have conducted a large quantity of research on PAHs [39] and reported the synthesis of 2D graphene ribbons with $12 \mathrm{~nm}$ length through the coupling of 1,4-diido-2,3,5,6-tetraphenylbenzene with 4-bromophenylboronic acid [40]. They have also reported the synthesis of GNR's on gold surface through bottom-up method, see Figure 5 [41].

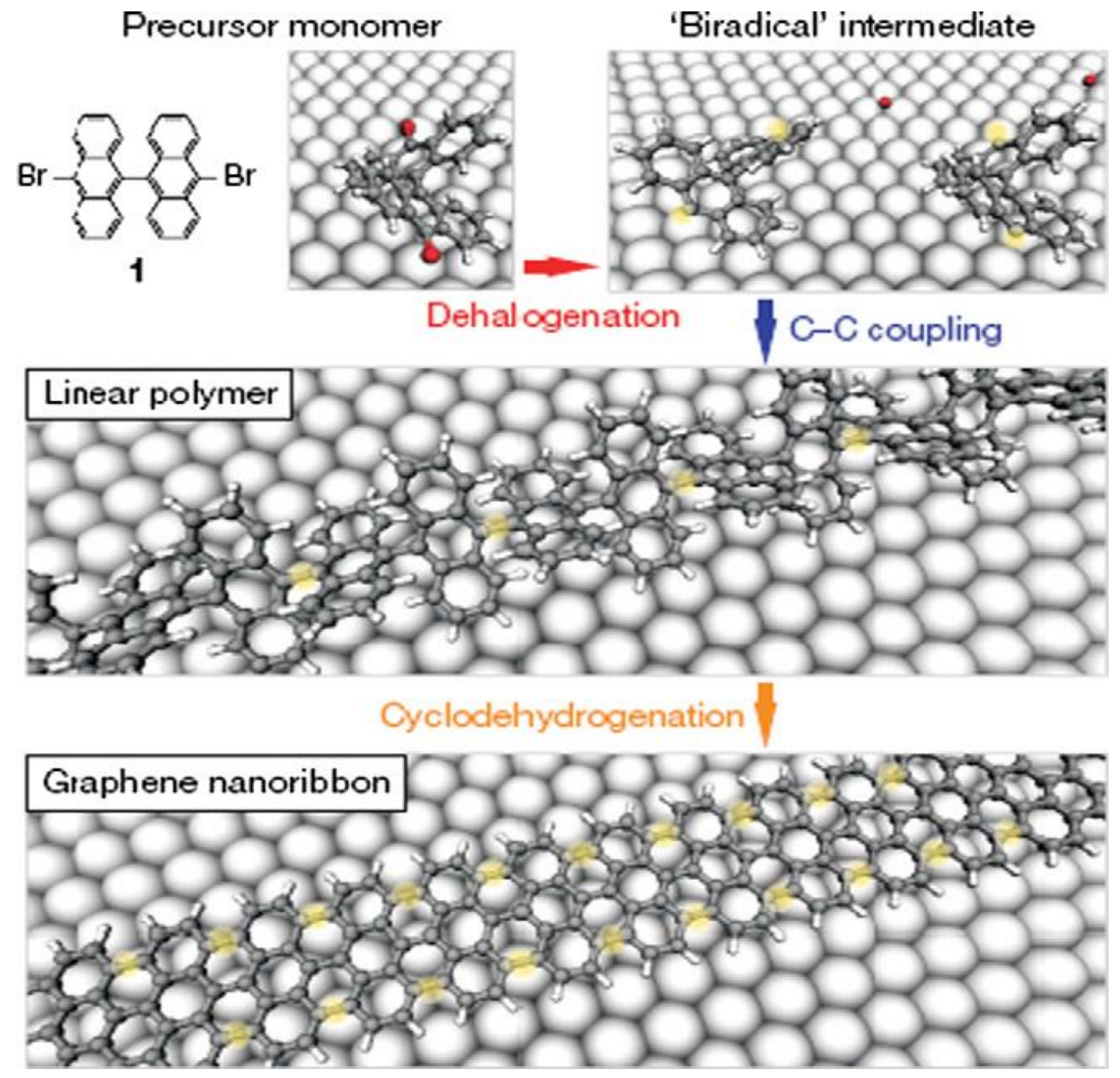

Figure 5: Sequential steps followed during the synthesis of GNR using bottom-up approach [41].

The synthesis includes dehalogenation in which halogens can be removed from the precursors using thermally deposited monomers on a gold surface. This facilitates the formation of surface-stabilized bi radical species that can diffuse across the surface to form the linear polymer chains during the first 
thermal activation. It can also be noted from the results that the bottom-up approach is one of the versatile techniques to produce GNR with better control over the structure and compositions resulting in superior electrical and mechanical properties.

\subsubsection{Synthesis of graphene nanoribbons (GNR) by unzipping CNT's}

In order to use graphene in semiconductor devices, the major aim is to incorporate an energy gap in graphene of this zero gap material. This can be achieved in two different approaches, controlled oxidation of FLG and synthesis of GNR. Researchers have predicted that the GNR with a width of 10 $\mathrm{nm}$ has band gaps for transistors at room temperature. GNRs possess smooth edges and provides high switching speed and carrier mobility for transistor operations [42-45]. Han et al. [46] have reported the synthesis of GNR of $20 \mathrm{~nm}$ width from graphene sheets through e-beam lithography. Even though the method reported to produce GNRs is straight forward, the produced GNR can have edge roughness. Jaio et al. [47] have reported an innovative method of producing GNR through unzipping CNTs by an Ar plasma etching method. This method includes the embedding of multi-walled CNTs (MWCNTs) in polymethyl methacrylate (PMMA) layer on a Si substrate. After baking, the PMMA/MWCNT is dipped in $\mathrm{KOH}$ solution and peeled off, this leads to exposing of the MWCNT to the Ar plasma treatment. The unzipped CNT/GNR can be obtained by etching the exposed MWCNT area, it can be noted that the exposed area can be etched faster than that are covered by PMMA. The diameter of CNT, the number of layers of MWCNT and etching time are the important factors that affect the formation of mono, biand multi-layer GNRs. By characterization of the GNRs obtained by unzipping the MWCNTs by Atomic force microscopy (AFM), it was noted that the produced GNRs have smooth edges. Raman spectroscopy data provide quantitative information about the $\mathrm{D}$ band and $\mathrm{G}$ bands, from this $\mathrm{I}_{\mathrm{D}} / \mathrm{I}_{\mathrm{G}}$ was calculated and the values measured were $0.38,0.3$ and 0.28 for mono, bi- and multi-later respectively, which indicates the high quality of the graphene [47]. Recent work reported by Schimizu et al. [48] have demonstrated the synthesis of GNR through oxidation and unzipping MWCNT in concentrated $\mathrm{H}_{2} \mathrm{SO}_{4}$ and treating it with $\mathrm{KMnO}_{4}$. The AFM and Raman spectroscopy results reported have shown the presence of surface defects due to the inefficient removal of oxidized groups, which in turn affect the electrical properties. Although the graphene synthesised through unzipping methods have shown superior electrical properties than the mechanically peeled graphene sheets [48-54] there is still a long way to go for the GNRs to be industrially applicable to produce transistors due to the lack of optimised parameters to produce defect free, highly oriented and high-quality graphene sheets.

\subsection{Synthesis of graphene oxide (GO) and reduced graphene oxide (rGO)}


Due to the high costs related to the synthesis of graphene, the chemical conversion of graphite into GO is a promising economical alternative to the graphene [55-57]. The molecular structure of GO and rGO are shown in Figure 7 [58]. From the molecular structure it can be noted that the GO is heavily oxygenated by hydroxyl and epoxy groups on $\mathrm{sp}^{3}$ hybridized carbon and carbonyl, carboxyl groups on $\mathrm{sp}^{2}$ hybridized carbon. This leads to the hydrophilic nature of GO and can be easily exfoliated in aqueous solution. GO is a monolayer material produced from exfoliation and have similar chemical properties as that of the graphite oxide. It can also be noted that the existence of hydroxyl and epoxy functional groups disrupts the electronic structure and GO behaves as an insulating material with irreversible defects and it has been suggested that chemical reduction could partially restore its conductivity $[11,59,60]$. The most popular method of synthesising GO through oxidizing graphite is the Hummers method [61]. This method involves oxidizing graphite using oxidants like $\mathrm{H}_{2} \mathrm{SO}_{4}, \mathrm{HNO}_{3}$ and $\mathrm{KM}_{\mathrm{n}} \mathrm{O}_{4}$. The GO films produced are thicker than the pristine graphene sheets of $0.34 \mathrm{~nm}$ thick due to the displacement of $\mathrm{sp}^{3}$ hybridized atoms. The synthesis of GO has been completed by the Brodie [62], Staudenmaier [63] or Hummers methods [61]. The oxidizers used by Brodie and Staudenmaier to oxidize graphite includes a combination of $\mathrm{KClO}_{3}$ with $\mathrm{HNO}_{3}$. Yanwu et al. [64] have reported the use of graphite salts that were made by intercalating graphite with acids like $\mathrm{H}_{2} \mathrm{SO}_{4}, \mathrm{HNO}_{3}$ or $\mathrm{KClO}_{4}$ as precursors for the oxidation of GO.

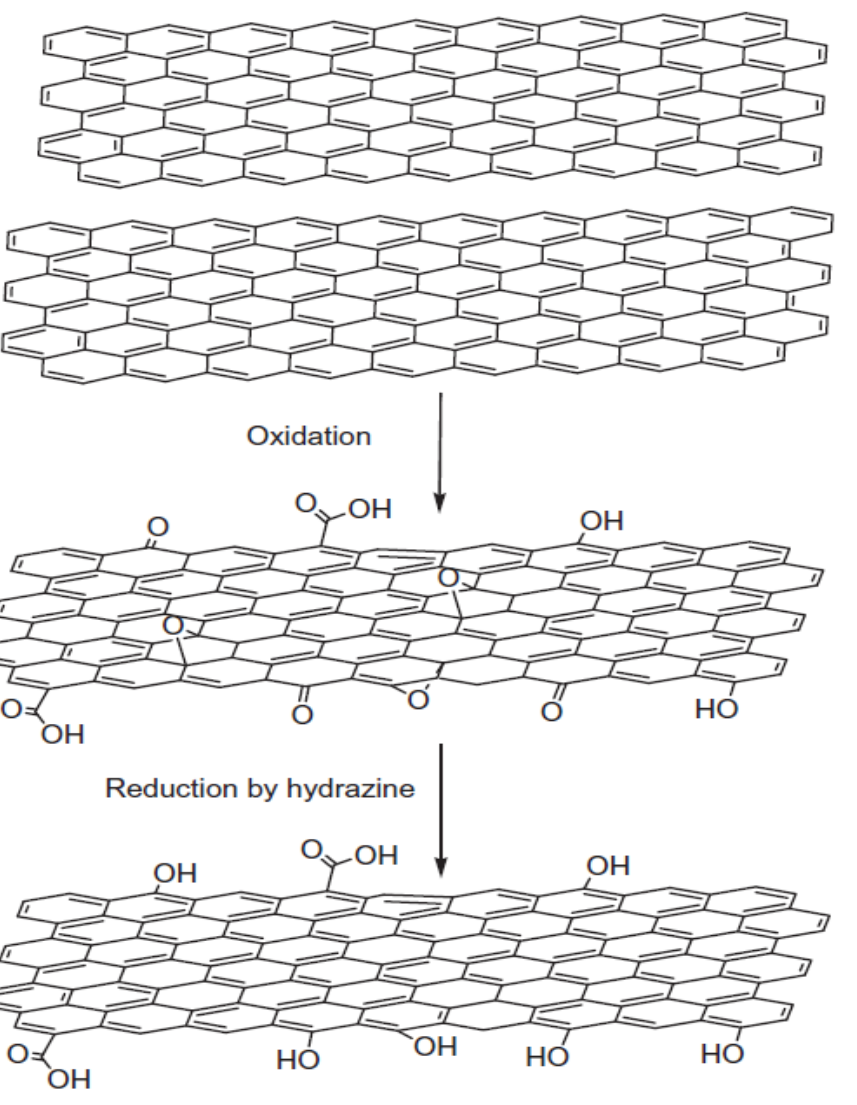

Figure 7: Oxidation of graphite to GO and reduction of GO to rGO [58]. 
The chemical reduction of GO sheets can be performed in the presence of different reducing agents, including hydrazine [12,57,65-67], sodium borohydride [60,68,69], hydroquinone [70] and ascorbic acid [71]. Out of all the reducing agents hydrazine hydride was referred as the best reducing agent to produce very thin graphene sheets, additionally, it does not react with water. During the reduction process, the oxygen atoms can be removed, which results in less hydrophilic nature of GO sheets [11,59]. The molecular structures of GO during oxidation and reduction of GO using hydrazine are shown in Figure 7 [58]. It can also be noted that the rGO can tend to agglomerate due to the hydrophobic nature until and unless stabilized by the selected surfactants. $\mathrm{NaB}_{4}$ is another reducing agent that effectively reduces the $\mathrm{GO}[60]$ and it is also reported that $\mathrm{NaB}_{4}$ is more effective than hydrazine but the problem with $\mathrm{NaB}_{4}$ is slow hydrolization by water. Athansios et al. [60] have reported the production of $\mathrm{rGO}$ using $\mathrm{NaB}_{4}$ and the comparison of rGO obtained by two different reducing agents hydrazine and $\mathrm{NaB}_{4}$ was also reported. It can be noted from their results that $\mathrm{rGO}$ obtained by using $\mathrm{NaB}_{4}$ has a low sheet resistance of $59 \mathrm{k} \Omega$ /square compared to that of the rGO produced using hydrazine of $780 \mathrm{k} \Omega /$ square and high $\mathrm{C}: \mathrm{O}$ ratio of 13.4:1 compared to that of the rGO produced using hydrazine of $6.2: 1$. Out of all the chemical reduction processes, reduction by hydrogen proved to be effective with C:O ratio of 10.8-14.9:1.

The thermal reduction is another way of reducing GO that involves the removal of oxide functional groups by heat treatment. Allister et al. [72] have reports the removal of oxide functional groups as $\mathrm{CO}_{2}$ by heating $\mathrm{GO}$ to $1050^{\circ} \mathrm{C}$. It was reported from the AFM study that the thermal reduction can reduce $\sim 80 \%$ single layer $\mathrm{rGO}$, whereas $30 \%$ of mass can be lost due to the removal of oxide functionalities which leaves vacancies and structural defects that may affect the mechanical and electrical properties of the produced rGO [56]. An approach that provides rGO at low temperatures is proposed by Dubin et al. [73]. This involves the production of rGO dispersion in organic solvents like N-methyl-2-pyrrolidinone (NMP) at $200^{\circ} \mathrm{C}$.

It is important to control the exfoliation behaviour of $\mathrm{GO}$ and $\mathrm{rGO}$ which helps in widening their potential applications, which can be achieved using surface functionalization of GO. There are two mechanisms in surface functionalization, covalent functionalization and non-covalent functionalization. In order to change the surface functionality of GO, if the oxygen functional groups on GO surfaces that include carboxylic acid groups at the edge of the epoxy/hydroxyl groups on the basal plane are used then it is called covalent functionalization. The carboxylic acid groups should be activated in order to use them on GO to stabilize other molecules. This activation can be either thionyl chloride [74], 1ethyl-3-carbodiimide [75], N, N- di cyclohexyl carbodiimide [76]. The weak $\pi-\pi$ interactions between the GO and target molecules can be used to functionalize GO in non-covalent functionalization. The conjugated polymers and aromatic compounds can be used to stabilise the rGO resulted from reduction 
reaction and can be used in the production of composite materials. The conjugated and aromatic polymers used are sulfonated polyaniline [77], conjugated polyelectrolyte [78], porphyrin [79] and cellulose derivatives [80]. The summary of advantages and disadvantages of various synthesis techniques is given in Table 1.

Table 1: Summary of advantages and disadvantages of graphene synthesis techniques.

\begin{tabular}{|c|c|c|c|}
\hline $\begin{array}{l}\text { Manufacturing } \\
\text { method }\end{array}$ & Advantages & Disadvantages & Cost effectiveness \\
\hline $\begin{array}{l}\text { Exfoliation } \\
{[10]}\end{array}$ & $\begin{array}{l}\text { This is a relatively } \\
\text { simple technique of } \\
\text { peeling graphene } \\
\text { sheets using adhesive } \\
\text { tape. }\end{array}$ & $\begin{array}{l}\text { Graphene sheets produced } \\
\text { by this process will be of } \\
\text { several sizes, irregular } \\
\text { shapes and orientations. This } \\
\text { will reduce the applicability } \\
\text { of graphene in potential } \\
\text { applications. }\end{array}$ & $\begin{array}{l}\text { Low- budget technique but this } \\
\text { has less relevance to the } \\
\text { commercial high-end } \\
\text { applications. }\end{array}$ \\
\hline $\begin{array}{l}\text { Chemical } \\
\text { vapour } \\
\text { deposition } \\
\text { (CVD) [28] }\end{array}$ & $\begin{array}{l}\text { This technique } \\
\text { provides } \\
\text { advantage of selection } \\
\text { of host substrate } \\
\text { independent of the } \\
\text { growth surface. This } \\
\text { process facilitates the } \\
\text { large scale production } \\
\text { of graphene by } \\
\text { limiting the size of } \\
\text { substrate to the size of } \\
\text { reactor. Mono layer } \\
\text { and bi-layer graphene } \\
\text { sheets can be obtained } \\
\text { using this process. }\end{array}$ & $\begin{array}{l}\text { The transfer process often } \\
\text { effects the integrity and } \\
\text { performance of the produced } \\
\text { graphene. Moreover, the } \\
\text { transfer process enhances the } \\
\text { formation of wrinkles, } \\
\text { impurities and structural } \\
\text { defects. }\end{array}$ & $\begin{array}{l}\text { Less-costly process as the cost } \\
\text { per unit area of graphene } \\
\text { produced will be limited to the } \\
\text { size of the substrate. The } \\
\text { selection of substrate often } \\
\text { effects the cost of the process. }\end{array}$ \\
\hline $\begin{array}{l}\text { Organic } \\
\text { synthesis [41] }\end{array}$ & $\begin{array}{l}\text { This approach has an } \\
\text { advantage of } \\
\text { versatility and PAH's } \\
\text { produces by this }\end{array}$ & $\begin{array}{l}\text { Size of the sheets produced } \\
\text { from this process is limited } \\
\text { due to the reduction of } \\
\text { solubility and increase in }\end{array}$ & $\begin{array}{l}\text { The cost incurred in } \\
\text { characterising the products of } \\
\text { chemical reactions is high. }\end{array}$ \\
\hline
\end{tabular}




\begin{tabular}{|c|c|c|c|}
\hline & $\begin{array}{l}\text { method can be } \\
\text { substituted } \\
\text { aliphatic chains to } \\
\text { modify the solubility. }\end{array}$ & $\begin{array}{l}\text { unwanted side reactions. } \\
\text { These reactions lead to } \\
\text { difficulties in dispersion } \\
\text { preservation. }\end{array}$ & \\
\hline $\begin{array}{l}\text { Chemical } \\
\text { derivation of } \\
\text { graphene } \\
\text { (production of } \\
\text { GO and rGO) } \\
\text { [61-63] }\end{array}$ & $\begin{array}{l}\text { This is the most viable } \\
\text { technique to obtain } \\
\text { graphene from } \\
\text { graphite. Nearly } 80 \% \\
\text { of single layer rGO } \\
\text { sheets can be obtained } \\
\text { through this process. } \\
\text { The electrical } \\
\text { conductivity can be } \\
\text { partly restored during } \\
\text { reduction process but } \\
\text { will still be less than } \\
\text { pristine graphene }\end{array}$ & $\begin{array}{l}\text { The formation functional } \\
\text { groups during the oxidation } \\
\text { process leads to the } \\
\text { irreversible effects to the } \\
\text { band structure and reduces } \\
\text { the electrical conductivity. }\end{array}$ & $\begin{array}{l}\text { This is the most affordable } \\
\text { technique to produce graphene. }\end{array}$ \\
\hline
\end{tabular}

\section{SYNTHESIS OF GRAPHENE-NANO PARTICLE (GNP) COMPOSITES}

Graphene nanoparticles (NP) have been explored for many potential applications. After the discovery of graphene, interest grew to their incorporate in various metals, metal oxide and semiconductors, aiming at obtaining a composite with better properties. However, there are some issues related to the production of graphene NP composites that need to be addressed. This includes separation of graphene sheets, non-uniform dispersion of NP on to the graphene sheets, the interaction of NP and graphene and the effect of size and defects of graphene sheets. There are three main stages in the synthesis of GNP composites, pre-graphenization, post-graphenization and syn-graphenization. Pre-graphenization involves the mixing of rGO with pre-synthesized rGO to produce the composite material. However, this process is limited to the organic solvents due to the hydrophobic nature of rGO. Post-graphenization involves the preparation of composite at primary level and the reduction of GO can take place after the production of the composite. This technique is most applicable to deposit metal and metal oxide NPs and semiconducting NPs onto the GO followed by reduction to form the composite. Syn-graphenization involves the use of stabilizer (second component of composite) to improve composite properties. Several rGO/GNP composites were reported in the literature based on the above three methods, some of shown in Table 2. 
Table 2: Overview of methods presented in the literature for the synthesis of GNP based composites.

\begin{tabular}{|c|c|c|c|}
\hline $\begin{array}{l}\text { Base } \\
\text { material }\end{array}$ & $\begin{array}{l}\text { Method of } \\
\text { Graphenization }\end{array}$ & Synthesis and reduction agents used during synthesis & $\begin{array}{l}\text { Refere } \\
\text { nce }\end{array}$ \\
\hline $\mathrm{Au}$ & Post & $\begin{array}{c}\text { Au NPs formation by reduction } \\
\text { of } \mathrm{Au} \text { ions in a gold salt solution on the RGO } \\
\text { films }\end{array}$ & {$[81]$} \\
\hline $\mathrm{Pt}$ & Pre & $\begin{array}{c}\mathrm{N} \text { doped } \mathrm{RGO}+\mathrm{DMF}+\mathrm{NaOH}+\text { ethylene glycol }+ \\
\qquad \mathrm{H}_{2} \mathrm{PtCl}_{6}+6 \mathrm{H}_{2} \mathrm{O}\end{array}$ & {$[82]$} \\
\hline $\mathrm{Pd}$ & Pre & $\mathrm{H}_{22}$ electrochemical plasma $\mathrm{rGO}+\mathrm{Na}_{2} \mathrm{PdCl}_{4}+\mathrm{LiClO}_{4}$ & {$[83]$} \\
\hline $\mathrm{SnO}_{2}$ & Pre & $\mathrm{RGO}+\mathrm{SnO}$ & {$[84]$} \\
\hline $\mathrm{TiO}_{2}$ & Post & $\mathrm{TiO}_{2}+\mathrm{GO}+$ antanase hydrothermal treatment & {$[85]$} \\
\hline $\mathrm{Ag}$ & Syn & $\begin{array}{c}\text { Heating } 75 \text { CGO on 3-aminopropyltriethoxysilane } \\
+ \text { AgNPs }\end{array}$ & {$[86]$} \\
\hline $\mathrm{Fe}_{3} \mathrm{O}_{4}$ & Pre & $\begin{array}{l}\text { Reaction of ferric } \\
\text { triacetyl acetonate with GO in 1-methyl-2pyrrolidone }\end{array}$ & {$[87]$} \\
\hline $\mathrm{TiO}_{2}$ & Syn & $\mathrm{GO}+\mathrm{TiCl}_{3}+\mathrm{H}_{2} \mathrm{O}$ in $\mathrm{SDS}$ solution & {$[88]$} \\
\hline $\mathrm{Mn}_{3} \mathrm{O}_{4}$ & Post & $\begin{array}{c}\mathrm{Mn}_{3} \mathrm{O}_{4} \text { on } \mathrm{GO}, 2 \text { step method }\left(\mathrm{Ni}(\mathrm{OH})+\mathrm{GO}, \mathrm{TiO}_{2}+\mathrm{GO}\right)+ \\
\mathrm{KMnO}_{4}\end{array}$ & {$[89]$} \\
\hline $\mathrm{Fe}_{3} \mathrm{O}_{4}$ & Post & $\begin{array}{l}\mathrm{GO}+\mathrm{Fe}_{3} \mathrm{O} \text { functionalizing with TEOS and magnetic } \\
\text { separation }\end{array}$ & {$[90]$} \\
\hline $\mathrm{Fe}_{3} \mathrm{O}_{4}$ & Post & $\mathrm{GO}+\mathrm{Fe}(\mathrm{DXR})_{3} \mathrm{O}_{4}+$ doxorubicin hydrochloride & {$[91]$} \\
\hline
\end{tabular}

In-situ growing of GNP is one of the techniques that were derived from growing CNT's. This technique facilitates the direct contact between graphene sheets and NP and homogeneous distribution of NP's due to nucleation of NPs in situ. Wang et al. [92] have suggested the use of carboxylic, hydroxyl and epoxy groups as the nucleation sites on GO to facilitate the control of morphology and crystallinity of NPs. They have also demonstrated the growth mechanisms of $\mathrm{Ni}(\mathrm{OH})_{2}$ on $\mathrm{GO}$ and rGO sheets. Solvothermal synthesis is another technique to produce rGO/NP composites without any addition of reducing agents. This can be simply referred as a syn-graphenization technique which involves the reduction process result of high temperature and pressure during the solvothermal reaction. This technique is beneficial in preventing the aggregation of graphene layers [93]. The electrical properties such as conductivity is slightly higher than the rGO obtained through reduction using hydrazine [94]. Even though this method facilitates the better properties this possesses the disadvantages of poor dispersion of GO in organic solvents and lack of control of functional groups on GO and rGO surfaces. 
Watcharotone et al. [95] have reported the use of sol-gel methods to synthesize graphene/silica composite thin films, this involves the hydrolysis of tetra methyl ortho silicate in GO suspension in water followed by the reduction using hydrazine. UV assisted reduction was another technique used to synthesis $\mathrm{rGO} / \mathrm{NP}$ composites. This involves photocatalytic reduction of GO under UV in the presence of $\mathrm{TiO}_{2}$ [96]. This method is relatively fast and avoids chemical reduction but has a limitation of applicability to only external light irradiation sensitive NP systems.

\section{PROPERTIES OF GRAPHENE}

In the past decade, the research on graphene has been increased tremendously due to its fascinating properties such as absorption of visible light of 2.3\% [97], the highest theoretical surface area of 2600 $\mathrm{m}^{2} / \mathrm{g}$ and minimum hall conductivity of $4 \mathrm{e}^{2} / \mathrm{h}$ [10]. This section of the paper includes exploring the electrical, mechanical and thermal properties which provide the wide range of potential applications of graphene.

\subsection{Electrical properties}

Pristine graphene is a zero-gap semiconductor. The extraordinary nature of charge carriers is one of the most notable aspects about graphene. The charge carriers in graphene behave as Dirac fermions (massless relativistic particles) and these behave abnormally compared to electrons when subjected to magnetic field [98], this was even observed at room temperatures. The low defect density of graphene's crystal lattice leads to high quality of single layer graphene sheets which is the main reason behind the high electrical conductivity of monolayer graphene sheets. The electrons in graphene behave as particles of light that do not scatter, which makes graphene a good conductor of electricity. Interfacial phonons [99], substrate ripples [100] and surface charge traps [101] are the factors that affect the conductivity of graphene sheets. Bolotin et al. [102] have demonstrated the minimum scattering using monolayer graphene layer in a suspended condition and demonstrated the effect of impurities on the surface of graphene sheets. A bipolar electrical field effect is another important characteristic of monolayer graphene sheets, this means by applying a gate voltage the charge carriers can be tuned between electrons and holes [103]. The major hurdle for graphene in potential applications is its zero energy gap, for eg: Field effect transistor, which needs on/off switch. Recent research in the area of graphene have reported the modification of graphene band structure by constraining graphene in nanoribbons [42,46,110] and graphene in quantum dots [105] and by biasing bi-layer graphene $[112,113]$. Evaldsson et al. [108] have reported the variation of the width of ribbons and disorders in the edges of both zigzag and armchair nanoribbons, this observation was supported by both experimental results and theoretical explanation. 
Due to the advantage of scalability to electronics, epitaxial graphene has gained a lot of interest in recent years. There was a mixed opinion among researchers about the bandgap opening in epitaxial graphene, zero band gap on graphene layers was reported by Pen et al. [109] whereas $0.26 \mathrm{eV}$ was reported by Kim et al. [110]. An innovative method of growing epitaxial graphene on SiC substrate was developed by De heer et al. [111], it was reported that the mobility of graphene grown on Si-terminated face is less than that of the graphene grown on carbon-terminated face, this is due to the difference in structures and this can also be gated. They have also reported the reduction in energy gap with an increase in thickness and it can be zero if the number of layers exceeds four. This matches well with observations reported by Peng et al. [109], in which energy gap was $0.26 \mathrm{eV}$ for mono layer graphene $0.14 \mathrm{eV}$ for the triple layer. Reina et al. [112] have used CVD to synthesise graphene layers on $\mathrm{Ni}$ substrate and reported a huge variation in filed effect mobility of $100-2000 \mathrm{~cm}^{2} / \mathrm{Vs}$ due to ineffective modulated resulted from the non-homogenous thickness of graphene films. Kim et al. [113] have synthesised graphene layers through CVD technique on $\mathrm{Ni}$ and transferred it to $\mathrm{SiO}_{2}$ substrate and the charge mobility was measured as $3700 \mathrm{~cm}^{2} / \mathrm{Vs}$ which confirm the existence of mono layer graphene. Even though $\mathrm{Ni}$ is the most used metallic substrate to grow graphene [20,22,118,119] of high quality, this suffers a drawback of solubility carbon-nickel and deposition of multi layers at grain boundaries. Copper was used as an alternative to $\mathrm{Ni}$ to overcome the difficulty of high solubility. It was reported that the graphene layer is grown on copper foil through CVD shown a mobility of $4050 \mathrm{~cm}^{2} / \mathrm{Vs}$ [23] and a mobility of $\sim 3000 \mathrm{~cm}^{2} / \mathrm{Vs}$ [20] by depositing graphene film on a large wafer of the copper substrate. The existence of difficulties in the synthesis of mono layer graphene sheets leads to the research related to the production of bi-layer and FLG. Novoselov et al. [114] reported that bi-layer graphene is almost gapless and remains metallic at neutrality points and charge particles are similar to that of the massless Dirac fermions but possess a finite mass and are called as massive Dirac fermions. Castro et al. [115] have reported a possibility of using bi-layer graphene as a tunable energy band gap semiconductor for energy applications by tuning the band gap by applying a magnetic field and it can be tuned up to $0.2 \mathrm{eV}$.

Numerous efforts have been made so far to reduce GO effectively in order remove oxygenated functional groups which incorporate the high electrical resistance $4 \mathrm{M} \Omega$ /square. It can also be noted that the thermal and chemical reduction can partially restore the electrical conductivity but introduces the structural defects that degrade the electrical properties compared to graphene. Gomez et al. [116] have measured the mobility and conductivity of $\mathrm{rGO}$ as $2-200 \mathrm{~cm}^{2} / \mathrm{Vs}$ and $0.05-2 \mathrm{~S} / \mathrm{cm}$ respectively. Li et al. [117] have reported the production of graphene nano sheets (GNS) and $72 \mathrm{~S} / \mathrm{m}$ of electrical conductivity at room temperature was noted from the observations, however the conductivity of the GNS obtained was not promising. The recent results published by researchers from Graphenea Spain, 
have reported that the electrical conductivity of $\mathrm{rGO}$ reached to a value of $666.7 \mathrm{~S} / \mathrm{m}$ for a film of $20 \mathrm{~nm}$ thickness [118]. Table 3 gives the overview of electrical properties of graphene and its derivatives from the most recent studies.

Table 3: Electrical properties of graphene and its derivatives.

\begin{tabular}{|c|c|c|c|c|}
\hline Material & $\begin{array}{c}\text { Electrical } \\
\text { conductivity (S/m) }\end{array}$ & $\begin{array}{c}\text { Electron charge } \\
\text { mobility } \\
\left(\mathrm{cm}^{2} / \mathrm{Vs}\right)\end{array}$ & Energy gap (eV) & Reference \\
\hline $\begin{array}{c}\text { Graphene(mono } \\
\text { layer) }\end{array}$ & $10^{8}$ & $15,000-200,000$ & 0.26 & {$[115]$} \\
\hline $\begin{array}{c}\text { Reduced graphene } \\
\text { oxide (rGO) }\end{array}$ & 666.7 & $17-2000$ & Tunable gap of \\
$0.35-0.78$ & {$[116,118]$} \\
\hline $\begin{array}{c}\text { Graphene nano sheets } \\
\text { (GNS - bi- layer/ tri- } \\
\text { layer/multi layers) }\end{array}$ & 72 & $290-5$ & 0.14 & \\
\hline
\end{tabular}

\subsection{Mechanical properties}

In any practical applications, an external application of stress and unwanted strain affect the performance and durability. The inter atomic distances of a crystalline material can be effected by the external stresses on the crystalline material this leads to the redistribution of local charge. This in turn, affects the electronic transport due to the development of band gap in the electronic structure. It was anticipated by researchers that graphene outperforms CNT's with high strength and stiffness. Lee et al. [7] have used AFM to measure the elastic properties of mono layer graphene and reported Young's modulus of $1 \pm 0.1$ Tpa and intrinsic strength of 130 \pm 10 Gpa. Tsoukleri et al. [119] have used Raman spectroscopy to measure the strain by applying compression and tension loads to the graphene mono layer and reported a strain of $1.3 \%$ and $0.7 \%$ in tension and compression respectively. Lee et al. [120] have reported the use of AFM to measure Young's modulus and strength of graphene and reported Young's modulus of $1.02 \mathrm{Tpa}, 1.04 \mathrm{Tpa}$ and $0.98 \mathrm{Tpa}$ and fracture strength of $130 \mathrm{Gpa}, 126 \mathrm{Gpa}$ and $101 \mathrm{Gpa}$ respectively for mono layer, bi-layer and tri-layer graphene. It can be noted that the increase number of layers increases the sliding tendency hence reduces the properties. Raman spectroscopy can be used to measure the compressive and tensile strains in graphene sheets by measuring the change in $G$ and 2D peaks with applied stress. Ni et al. [121] have mentioned that it is possible to tune the band gap by introducing a controlled strain, as the strain may change electric band structure. Cristina et al. [122] have reported that the successful production of chemically modified graphene by reducing graphene 
oxide with hydrogen plasma, Young's modulus of 0.25 Tpa was noted from the results. Peng et al. [123] have reported the fracture toughness of pristine graphene as $4 \mathrm{Mpa} \sqrt{m}$, it can be noted from the values that the graphene tends to form agglomerates and imperfections in graphene leads to the brittle nature. There is still more research need to be done in unfolding the mechanical and structural capabilities of graphene. Table 4 gives the overview of mechanical properties of graphene and its derivatives, it can be noted from the table that Increase number of graphene nano sheet layers leads to the detoriation in properties.

Table 4: Mechanical properties of graphene and its derivatives.

\begin{tabular}{|c|c|c|c|c|}
\hline Material & $\begin{array}{l}\text { Young's modulus } \\
\text { (Mpa) }\end{array}$ & $\begin{array}{l}\text { Tensile strength } \\
\text { (Mpa) }\end{array}$ & $\begin{array}{l}\text { Fracture toughness } \\
\qquad(\mathrm{Mpa} \sqrt{m})\end{array}$ & Reference \\
\hline $\begin{array}{c}\text { Graphene (mono } \\
\text { layer) }\end{array}$ & $10^{6}$ & $1.3 \times 10^{5}$ & $4-5$ & {$[120,123]$} \\
\hline $\begin{array}{c}\text { Reduced graphene } \\
\text { oxide (rGO) }\end{array}$ & $2.5 \times 10^{5}$ & $0.9 \times 10^{3}$ & $2.8-3$ & [122] \\
\hline $\begin{array}{c}\text { Graphene nano } \\
\text { sheets (GNS - bi- } \\
\text { layer/ tri-layer/multi } \\
\text { layers) }\end{array}$ & $\begin{array}{c}1.04 \times 10^{6}-0.98 \\
\times 10^{6}\end{array}$ & $\begin{array}{c}1.26 \times 10^{5}- \\
1.01 \times 10^{5}\end{array}$ & $4.7-3.8$ & [120] \\
\hline
\end{tabular}

\subsection{Thermal properties}

Graphene finds most of its applications in the field of electronics as it is the best conductor of electricity known so far, thermal management is one of the major issues that needs to be addressed while working with the electrical devices. During the operation of the devices considerable amount of heat can be generated and dissipated. It is well known that the allotropes of carbon, i.e. graphite, diamond and CNT's possess high thermal conductivity due to the strong C-C covalent bonding. Until the arrival of graphene, single walled CNT's (SWCNT) and multi-walled CNT's (MWCNT) were known for having the highest conductivities of $3500 \mathrm{~W} / \mathrm{mK}$ and $3000 \mathrm{~W} / \mathrm{mK}[124,125,130,131]$. Blandin et al. [2] have reported that the thermal conductivity of monolayer graphene sheets as 5000 W/mK using confocal micro-Raman spectroscopy. Ghosh et al. [126] have reported the use of confocal Raman spectroscopy to measure the conductivity of suspended graphene flakes for thermal management applications and thermal conductivity of $4100-4800 \mathrm{~W} / \mathrm{mK}$ at room temperature was noted. Seol et al. [127] have used thermal measurement method to measure the conductivities of single layer graphene sheets suspended and on $\mathrm{SiO}_{2}$ support and reported conductivity of 3000-5000 W/mK 
and $600 \mathrm{~W} / \mathrm{mK}$ for suspended and on $\mathrm{SiO} 2$ respectively. There was a speculation among the researchers that the thermal conductivity of graphene was overly estimates and lee et al. [128] have reported the conductivity as $1200-2700 \mathrm{~W} / \mathrm{mK}$ and bi layer graphene as $600-500 \mathrm{~W} / \mathrm{mK}$ [129]. It can be noted that the electrical conductivity of graphene is affected by defect edge scattering and isotropic doping. The thermal properties of graphene and its derivatives are summarised in Table 5.

Table 5: Thermal properties of graphene and its derivatives.

\begin{tabular}{|c|c|c|}
\hline Material & Thermal conductivity (W/mK) & References \\
\hline Graphene & $1200-2700$ & {$[128]$} \\
\hline Reduced graphene oxide (rGO) & $30-250$ & {$[128]$} \\
\hline $\begin{array}{c}\text { Graphene nano sheets (GNS - } \\
\text { bi- layer/ tri-layer/multi layers) }\end{array}$ & $600-500$ & {$[129]$} \\
\hline
\end{tabular}

\section{APPLICATION OF GRAPHENE AND GNP BASED COMPOSITES}

The potential applications of graphene includes single molecule gas sensing, biomedical devices, transparent conducting electrodes, optoelectronic devices etc [58,136,137]. The main focus in this paper is given to energy storage and conservation. The exceptional properties of graphene i.e. high electrical conductivity and high surface area makes graphene a promising material for energy conversion and storage applications.

\subsection{Energy storage}

Lithium-ion batteries (LIB) are one of the best energy storage devices due to the advantages of longer cycle life, higher specific energy and its rechargeable characteristics. As mentioned earlier high chemical stability, high electrical conductivity and high surface to volume ratio makes it an ideal candidate for energy storage applications. The electrode materials that are being used in LIB at present include $\mathrm{SnO}_{2}, \mathrm{CO}_{3} \mathrm{O}_{4}, \mathrm{Fe}_{3} \mathrm{O}_{4}, \mathrm{TiO}_{2}$ and $\mathrm{MnO}_{2}$. Even though these materials have high theoretical capacities they would not perform as well in practical applications due to their lower electrical conductivity. Another major issue with LIBs at present are the chemical stability of the active material and decrease in cyclic performance. Recent research has suggested the incorporation of conductive materials such as CNT's and carbon particles to increase specific capacity [138-141]. Yoo et al. [136] have reported the use of GNS in rechargeable LIB and it was also reported the increase in specific capacity of the electrode through the interaction of GNS with C60 and CNT. Pan et al. [137] have demonstrated the application of disordered graphene sheets in LIB. It can be noted from their results 
that defected graphene sheets provide additional reversible storage sites for Li-ions. The problem with LIB using conventional materials can be avoided by the addition of graphene-based material to metal oxide which can improve the specific capacity and electrochemical stability for longer periods. This improvement can further increase the conductivity, specific area, stability and flexibility which are the principle requirements for an efficient energy storage. Graphene-encapsulated $-\mathrm{CO}_{3} \mathrm{O}_{4}$ was used as an anode material to improve the performance of LIB. It was reported that the energy density of 1100 $\mathrm{mAh} / \mathrm{g}$ and current density of $74 \mathrm{~mA} / \mathrm{g}$ [138]. Wu et al. [139] have reported that the synthesis of graphene-anchored $\mathrm{CO}_{3} \mathrm{O}_{4}$ as the anode material in LIBs to improve the capacity and cyclic performance and the values were noted as $935 \mathrm{mAh} / \mathrm{g}$ of energy density and $50 \mathrm{~mA} / \mathrm{g}$ of current density at 30 cycles. Wang et al. [89] have reported graphene- $\mathrm{Mn}_{3} \mathrm{O}_{4}$ as an anode material for LIB with current density of $400 \mathrm{~mA} / \mathrm{g}$ and energy density of $780 \mathrm{mAh} / \mathrm{g}$ and approximately 50 cycles. The same research group have reported $\mathrm{SnO}_{2}$-graphene material in energy storage application with energy density of 625 $\mathrm{mAh} / \mathrm{g}$ compared to pure $\mathrm{SnO}_{2}$ of $782 \mathrm{mAh} / \mathrm{g}$ [140] and current density of $10 \mathrm{~mA} / \mathrm{g}$. Zhou et al. [141] have reported graphene -wrapped $\mathrm{Fe}_{3} \mathrm{O}_{4}$ as anode material in LIB with improved capacity and chemical stability. It can also be noted that this material displays energy density of $1026 \mathrm{mAh} / \mathrm{g}$ and current density of $35 \mathrm{~mA} / \mathrm{g}$. Furthermore there are still some unanswered questions that need a more basic understanding of the chemical and thermal stability of the anodic material at various environments. Xiaojun et al. [142] have reported the use of $\mathrm{COsnO}_{3} / \mathrm{GN} / \mathrm{CNT}$ composite papers as the anodic material in LIB to enhance their performance. It was also reported the produced composite exhibits excellent cycle performance through filtration, transformation and heat treatment. Seung et al. [143] developed a new porous $\mathrm{MnO}_{3}$ nanorod/rGO hybrid paper as anode material for LIB. It was noted from the results that $\mathrm{PMn}_{3} \mathrm{O}_{4} \mathrm{NR} / \mathrm{rGO}$ paper exhibits high discharge capacity of $943 \mathrm{mAh} / \mathrm{g}$ than pristine graphene with $183 \mathrm{mAh} / \mathrm{g}$, it quickly attains stability.

Supercapacitors are another energy storage device that has caught the attention of many researchers due to their high power density, fast charge/discharge ability without degradation. Supercapacitors are used to store passive and static electrical energy and are mostly used in electronic gadgets and hybrid electric automobiles. Out of all the material used for capacitors, carbon-based materials are most commonly used due to high electrical conductivity, chemical and mechanical stability. The material with high specific capacitance plays a key role in efficient energy storage as the storing energy involves adsorption of ions onto electrodes that have high accessible surface area. As the graphene possess a high specific area of $2675 \mathrm{~m}^{2} / \mathrm{g}$ it can be reported as a potential candidate for supercapacitor applications. Xia et al. [144] have reported an intrinsic capacitance of $21 \mu \mathrm{F} / \mathrm{cm}^{2}$ of graphene, which has set a new upper limit for capacitance. Researchers have produced graphene -hydrous $\mathrm{RuO}_{2}$ in aqueous $\mathrm{KOH}$ electrolytic solution for the application in supercapacitors. It is noted that the material 
has displayed capacitance $135 \mathrm{~F} / \mathrm{g}$ in $\mathrm{KOH}$ electrolyte and $99 \mathrm{~F} / \mathrm{g}$ in organic solvents. Whereas, with the same electrolyte $\mathrm{KOH}$, the microwave-assisted reduction of $\mathrm{GO}$ has resulted in increased capacitance of $191 \mathrm{~F} / \mathrm{g}$ and reduced surface area of $463 \mathrm{~m}^{2} / \mathrm{g}$ [145]. On the other hand, the hydrazine reduced GO have displayed a surface area of $320 \mathrm{~m}^{2} / \mathrm{g}$ and specific capacitance of $205 \mathrm{~F} / \mathrm{g}$ [130]. Aggregation and vanderwalls attraction between the graphene layers are the major problems related to the use of rGO to use it in supercapacitor applications. Wu et al. [146] have reported the use of graphene-hydrous $\mathrm{RuO}_{2}$ in $1 \mathrm{M} \mathrm{H}_{2} \mathrm{SO}_{4}$ electrolytic solution in super capacitors, it can be noted that the produced composite displayed high capacitance of $570 \mathrm{~F} / \mathrm{g}$, the high energy density of $20.1 \mathrm{~W} \mathrm{~h} / \mathrm{kg}$ and power density of $10 \mathrm{KW} / \mathrm{kg}$. The same group produced $\mathrm{MnO}_{2}$ nano wire-graphene composite to improve the capacitance, it was reported that capacitance of the produced composite as $31 \mathrm{~F} / \mathrm{g}$ and power density as $30.4 \mathrm{~W} \mathrm{~h} / \mathrm{kg}$ [147]. Kai et al. [148] developed a nitrogen doped graphene for supercapacitor applications. The results have shown the NG exhibits an outstanding specific capacitance of $197 \mathrm{~F} / \mathrm{g}$ at a current density of $0.5 \mathrm{~A} / \mathrm{g}$ in $\mathrm{KOH}$ solution. In addition, it can be noted that the NGs displays the long term electrochemical stability. Manoj et al. [149] have developed an innovative electric double layer capacitor (EDLC) using plastic crystal based gel polymer electrode (GPE) and GNP as electrodes. It can be noted from the results that the EDLC showed a low specific energy of $8.2 \mathrm{Wh} / \mathrm{kg}$ and high power density of $4 \mathrm{~kW} / \mathrm{kg}$.

Yanping et al. [150] have demonstrated comparative study on thermal performance of PA-SA by adding GNP and EG. It was noted that at higher loads the thermal conductivity of the phase change material (PCM) was 2.7 times higher than GNP and 15.8 times higher than that of EG. The EG material can be seen then to possess the potential to evolve as an efficient thermal energy storage material. Mehrali et al. [151] have synthesised highly conductive palmitic acid/GO composites, this material finds applications in thermal energy storage. It was reported that PA/GO composites have shown an excellent thermal reliability and chemical stability and three times increase in thermal conductivity was recorded.

\subsection{Energy conversion}

Fuel cells are one of the promising energy conversion devices that have the advantages of high conversion efficiency, low operating temperature and ease of handling. Previously CNTs have been extensively investigated for fuel cell applications due to their enhanced catalytic activities $[158,159]$. However, this has changed after the invention of highly conductive 2D graphene sheets [160-163]. Fuel cells mainly consist of 3 parts: anode, cathode and a separation membrane. The most commonly used cathodic materials are $\mathrm{Pt}, \mathrm{Au}, \mathrm{Ru}$ and their alloys which are highly expensive $[164,165]$. Out of all 
these materials, Pt is most widely used the cathodic material for fuel cells which is expensive and at the same time less abundant as well. The Pt-based catalyst still suffer from poor tolerance due to the $\mathrm{CO}$ poisoning. It is really challenging to develop a metal free oxygen reduction reaction (ORR) catalysts with high current density and durable material to replace or to reduce Pt. one of such effort is a synthesis of Pt/graphene hybrids. Yoo et al. [160] have developed PtNP/GNS composites with a current density of $0.12 \mathrm{~mA} / \mathrm{cm}^{2}$ which is four times higher than that of the commercially available $\mathrm{Pt} / \mathrm{C}$ with $0.03 \mathrm{~mA} / \mathrm{cm}^{2}$. The $\mathrm{CO}$ absorption rate is 40 times smaller than that of the $\mathrm{Pt} / \mathrm{C}$, which shows that PtNP/GNS as the promising material for fuel cell applications. Choi et al. [161] have reported the potentiality of Pt deposited onto the surface of GNS using a surfactant as a cathode material for the fuel cell. It can be noted that the current density was increased to three times that of the Pt/c. Rong et al. [162] have reported the application of functionalized graphene sheets prepared by thermal expansion of GO and Pt/NP composite in a fuel cell. It was noted in their results that the ORR activity of Pt/FLG reached $49.8 \%$ whereas $\mathrm{Pt} / \mathrm{C}$ was at $33.6 \%$. Lee et al. [163] have developed Pt-BCN-Gr/CB hybrid catalyst of the polymer electrolyte fuel cell and demonstrated the effect of boron/nitrogen CO-doping into the graphene and intercalation of the produced hybrid catalyst. It can be noted from the results that $\mathrm{B}$ and $\mathrm{N}$ doping enhanced the cell performance about 28\%. Yang et al. [164] have demonstrated the PtB doped graphene intercalated by carbon black as a cathodic catalyst in the proton exchange membrane fuel cell. Pt-B-Gr/CB was shown to have better durability compared to conventional catalysts and ECSA increased with CB content. ECSA increased to $33.6 \mathrm{~m}^{2} / \mathrm{g}$ with $30 \mathrm{wt} \%$ of CB. Jing et al. [165] developed thermally rGO grown with CNT to use as a support for fuel cells. The results have shown that $\mathrm{rGO} / \mathrm{CNT}$ have exhibited a high electrical conductivity of $144.4 \mathrm{~S} / \mathrm{cm}$ and $\mathrm{Pt} / \mathrm{Gr}-\mathrm{CNT}$ have displayed a very high ECSA of $77.4 \mathrm{~m}^{2} / \mathrm{g}$.

\subsection{Graphene-based conductors}

Graphene is one of the best conductor known to us so far, which conducts electricity better than copper as the electrons and holes both act as charge carriers. Ivan et al. [131] have developed new graphenebased transparent conductors by intercalating $\mathrm{FLG}$ with $\mathrm{FeCl}_{3}$. It can be noted from the observations that these conductors display a sheet resistance of $8.8 \Omega /$ sq which is far less than the critical value of 30 $\Omega /$ sq for multi-layer [166] and $125 \Omega$ /sq for chemically derived graphene [167]. Sajid et al. [168] have reported the application of graphene-based conductors (GBC) as transmission lines (TL) and the coupling characteristics were investigated. The wave propagation of GBC transmission lines is similar to microstrip transmission lines and is less than $300 \mathrm{~dB}$ to $7 \mathrm{GHz}$. In addition, the GBC TL possess the capability to be evolved as a material for planar antenna arrays. In a review article written by Wang et 
al. [169], they demonstrate the possibility of graphene-based conductors in the area of light emitting diodes. It was also expected by these researchers that it is possible to obtain low sheet resistance by growing graphene directly through the CVD approach with tunnel junction design. Lee et al. [170] have reported the promising routes of producing graphene-based conductive films which open a new path for future electronic applications. It is noted that a sheet resistance of $50 \Omega /$ sq was observed with four layers of graphene.

\section{FUTURE PERSPECTIVE}

It is evident from the significant amount of increase in publications in last 5 years that graphene possess a capability to surpass the use of silicon in the field of electronics and the conventional materials used in energy storage and conversion devices. The extraordinary properties such as high electrical and thermal conductivities, strength makes graphene an ideal material for potential industrial applications. However these properties were observed in pristine graphene and chemically, thermally modified graphene displays the reduced properties than pristine but still better than most of the conventional materials. Graphene has opened a new path towards the micro and nano electronics with the tunable band gap using GNR and GNS that allows for the large scale production of field effect transistors (FET). Graphene is still a developing material and needs development in sophisticated characterization and synthesis techniques, CVD is one such technique that provides the growth of mono, bi-layer and few layer graphene sheets and the scalability of transferring the sheets for the fabrication of devices. The graphene sheets produces through the CVD process offers the exiting and potential in semiconductor applications. Extending CVD process further to a high quality and cleaner transfer process leads to the production of thermal management devices and transparent conductive electrodes. Controlling the formation of number of layers is one such issue that needs to be addressed and is a major focus of graphene research community. The major breakthrough occurred in the large scale production of graphene is by deriving graphene from chemically and thermally modifying GO in a highly economical way. However this process has the major disadvantage of reduction in thermal and electrical conductivities due to the lack of control of functionalization of groups. The band gap will be altered during this process which limits the applications of graphene. Hence the controlled modification of graphite into graphene is crucial in expanding the potential applications of graphene based materials. It can also be noted that majority of the researchers are still unware of the health issues that might be caused due to the handling of large scale graphene, this needs to be investigates together with the toxic effects of graphene based products on environment and their bio-degradability. Therefore it is advised to pursue the chemical and thermal modification of GO to rGO in controlled environments. 
The potential applications of graphene based materials includes electronic devices, thermal management devices, mechanical parts, energy storage, transparent conductive electrodes and biosensors. The major hurdle in using graphene as a reinforcement material composites applicable in industrial applications is its bonding with the matrix material, non-homogeneous distribution along the matrix, orientation of layers and existence of number of layers that effects the properties of graphene and needs more insight investigation. It is worth noting that the research in the area related rGO needs polishing in terms of investigating defects from the atomic level, formation of wrinkles and agglomerates. Most of the nano electronic devices produced using graphene include tuning the energy band gap but it is still a challenging aspect to create the energy gap while depositing the graphene layers. It can be noted from literature that for FET devices the GNR's are the correct choice and more insight of material properties and sophisticated characterisations are required. GO use in the production in FET's triggered interest among the researchers due its large scale integrity but there isn't sufficient amount of research evidence to support this, more atomic level analysis needs to be done to understand the existence of homogeneity at nano level. It can be suggested that GNR, GO can possess a capability to facilitate the tunable energy gap for the fabrication of nano electronic devices.

Graphene has a potential to replace the conventional re-inforcements for the metal matrix composites. Researchers have proven that using graphene and its derivatives as a reinforcement for aluminum matrix enhances the properties of base material, Al. 0.7 vol\% of few layer graphene as a reinforcement on $\mathrm{Al}$ matrix composite have shown an increase of $71.8 \%$ increase in tensile strength over the base material [171]. Rashad et al. [172] have re-ported the increase in $11.1 \%$ of tensile strength and $14.5 \%$ of yield strength over the pure Al with the addition of $0.3 \mathrm{wt} \%$ of GNP to Al. rGO has proven its potential as a promising reinforcement for $\mathrm{Al}$ matrix composites showing an increase of $62 \%$ in tensile strength [173], $18 \%$ in elastic modulus and $17 \%$ in hardness [174] than base material with the addition of $0.3 \mathrm{wt} \%$ of $\mathrm{rGO}$ to Al. Jing.et al. have reported the use of rGO [175] and GNS [176] as reinforcement for Al matrix composites. Authors used $0.07 \mathrm{wt} \%, 0.15 \mathrm{wt} \%$ and $0.3 \mathrm{wt} \%$ of rGO and GNS as reinforcement and reported the hardness increase of $11 \%, 16 \%$ and $32 \%$ for rGO and $1.9 \%, 21 \%$ and $43 \%$ for GNS respectively. Authors have published scientific journals with rGO and GNS as a reinforcement for pure $\mathrm{Al}$ and reported promising results with a high intention of extending this work to various wt $\%$ of reinforcement and wide range of base materials for potential industrial applications. 


\section{CONCLUSION}

In this article, the various production techniques of graphene were discussed along with $\mathrm{GO}, \mathrm{rGO}$ and GNP. The potential applications of graphene and graphene-based composites were reviewed. The CVD method of synthesising graphene possess the exceptional potential to be used in industrial production of graphene with the development of an efficient transfer process. It is necessary to control the level of defects and the number of layers of graphene formed such that the performance of graphene-based devices can be controlled, which is a main challenge for the material community. More research is needed to understand the formation of these layers and their performance in various applications. The synthesis of reduced graphene can evolve as a cost effective alternative for graphene in the industry with more of an understanding and control of reduction reactions. This postgraphitization method, along with these other exciting developments, opens up new paths towards energy-related applications including supercapacitors, photodetectors, electrochemical sensors, solar cells and transparent electrodes. To conclude the development and commercialization of these materials has been ongoing for more than 20 years. Based on these past and current efforts, graphene and GO based materials research and function development would be expected to continue at a fast pace unfolding new interesting properties and applications.

\section{REFERENCES}

[1] Novoselov KS, Geim AK, Morozov SV, Jiang D, Katsnelson MI, Grigorieva IV, et al. Twodimensional gas of massless Dirac fermions in graphene. Nature 2005;438:197.

[2] Balandin AA, Ghosh S, Bao W, Calizo I, Teweldebrhan D, Miao F, et al. Superior thermal conductivity of single-layer graphene. Nano Lett 2008;8:902.

[3] Lee C, Wei X, Kysar JW, Hone J. Measurement of the elastic properties and intrinsic strength of monolayer graphene. Science 2008;321:385.

[4] Fuzellier H, Melin J, Herold A. Conductibilité électrique des composés lamellaires graphiteSbcl5 graphite-SbCl5. Carbon 1977;15:45.

[5] Land TA, Michely T, Behm RJ, Hemminger JC, Comsa G. STM investigation of single layer graphite structures produced on $\operatorname{Pt}(111)$ by hydrocarbon decomposition. Surf Sci 1992;264:261.

[6] Nagashima A, Nuka K, Itoh H, Ichinokawa T, Oshima C, Otani S. Electronic states of monolayer graphite formed on TiC(111) surface. Surf Sci 1993;291:93.

[7] Berger C, Song ZM, Li TB, Li XB, Ogbazghi AY, Feng R, et al. Ultrathin epitaxial graphite: 2D electron gas properties and a route toward graphene-based nanoelectronics. J Phys Chem B 2004;108:19912.

[8] Wu J, Becerril HA, Bao Z, Liu Z, Chen Y, Peumans P. Organic solar cells with solutionprocessed graphene transparent electrodes. Appl Phys Lett 2008;92:263302.

[9] Xiang Z, Bhavatharini SR, Liu H and Ramakrishna S, Graphene's potential in materials science and engineering. RSC Advances, 55, 2014. 28987:29011.

[10] Novoselov KS, Geim AK, Morozov SV, Jiang D, Zhang Y, Dubonos SV, et al. Electric field 
effect in atomically thin carbon films. Science 2004;306:666.

[11] Stankovich S, Dikin DA, Piner RD, Kohlhaas KA, Kleinhammes A, Jia Y, et al. Synthesis of graphene-based nanosheets via chemical reduction of exfoliated graphite oxide. Carbon 2007;45:1558.

[12] Becerril HA, Man J, Liu Z, Stoltenberg RM, Bao Z, Chen Y. Evaluation of solution-processed reduced graphene oxide films as transparent conductors. ACS Nano 2008;2:463.

[13] Hernandez Y, Nicolosi V, Lotya M, Blighe FM, Sun Z, De S, et al. High-yield production of graphene by liquid-phase exfoliation of graphite. Nat Nanotechnol 2008;3:563.

[14] Kang FL, Zhang TY. Influences of H $2 \mathrm{O} 2$ on synthesis of H2SO-GICs. J Phys Chem Solids $1996 ; 57: 889.4$

[15] Kang F, Zhang TY, Leng Y. Electrochemical behavior of graphite in electrolyte of sulfuric and acetic acid. Carbon 1997;35:1167.

[16] Pan YX, Yu ZZ, Ou YC, Hu GH. A new process of fabricating electrically conducting nylon 6/graphite nanocomposites via intercalation polymerization. J Polym Sci Part B - Polym Phys 2000;38:1626.

[17] Zhuang J, Wang K, Jun Y, Tong W, Lin Z, Jing F, Yue-ming R, LiPing S and Fei W. Facile Synthesis of Graphene Nanosheets via Fe Reduction of Exfoliated Graphite Oxide. ACS Nano, 5, 2011, 191:198.

[18] Lei L, Jing X, Genghui L, Xilai J, Yongfeng L, Fan Y, Liqiang Z, Chunming X, Jinsen G, Yi L, Zhaowei F. Preparation of graphene nanosheets by shear-assisted supercritical $\mathrm{CO}_{2}$ exfoliation. Chemical Engineering Journal, 284, 2016, 78:84.

[19] Somani PR, Somani SP, Umeno M. Planer nano-graphenes from camphor by CVD. Chem Phys Lett 2006;430:56.

[20] Cao H, Yu Q, Colby R, Pandey D, Park CS, Lian J, et al. Large-scale graphitic thin films synthesized on Ni and transferred to insulators: Structural and electronic properties. J Appl Phys 2010;107:044310.

[21] Bhaviripudi S, Jia X, Dresselhaus MS, Kong J. Role of kinetic factors in chemical vapor deposition synthesis of uniform large area graphene using copper catalyst. Nano Lett 2010;10:4128.

[22] Kim KS, Zhao Y, Jang H, Lee SY, Kim JM, Kim KS, et al. Large-scale pattern growth of graphene films for stretchable transparent electrodes. Nature 2009;457:706.

[23] Li X, Cai W, An J, Kim S, Nah J, Yang D, et al. Large-area synthesis of high-quality and uniform graphene films on copper foils. Science 2009;324:1312.

[24] Chae SJ, Gunes F, Kim KK, Kim ES, Han GH, Kim SM, et al. Synthesis of large-area graphene layers on poly-nickel substrate by chemical vapor deposition: wrinkle formation. Adv Mater 2009;21:2328.

[25] Lee S, Lee K, Zhong Z. Wafer Scale homogeneous bilayer graphene films by chemical vapor deposition. Nano Lett 2010;10:4702.

[26] Lee Y, Bae S, Jang H, Jang S, Zhu S-E, Sim SH, et al. Wafer-scale synthesis and transfer of graphene films. Nano Lett 2010;10:409.

[27] Bae S, Kim H, Lee Y, Xu X, Park J-S, Zheng Y, et al. Roll-to-roll production of 30-inch graphene films for transparent electrodes. Nat Nanotechnol 2010;5:574. 
[28] Qu L, Liu Y, Baek J-B, Dai L. Nitrogen-doped graphene as efficient metal-free electrocatalyst for oxygen reduction in fuel cells. ACS Nano 2010;4:1321.

[29] Reddy ALM, Srivastava A, Gowda SR, Gullapalli H, Dubey M, Ajayan PM. Synthesis of nitrogen-doped graphene films for lithium battery applications. ACS Nano 2010;4:6337.

[30] Wang JJ, Zhu MY, Outlaw RA, Zhao X, Manos DM, Holoway BC. Free-standing subnanometer graphite sheets. Appl Phys Lett 2004;85:1265.

[31] Wang JJ, Zhu MY, Outlaw RA, Zhao X, Manos DM, Holoway BC. Synthesis of carbon nanosheets by inductively coupled radio-frequency plasma enhanced chemical vapor deposition. Carbon 2004;42:2867.

[32] Hass J, Heer WAd, Conrad EH. The growth and morphology of epitaxial multilayer graphene. J Phys: Condens Matter 2008;20:323202.

[33] De Heer WA, Berger C, Wu X, First PN, Conrad EH, Li X, et al. Epitaxial graphene. Solid State Commun 2007;143:92.

[34] Varchon F, Feng R, Hass J, Li X, Nguyen BN, Naud C, et al. Electronic structure of epitaxial graphene layers on SiC: effect of the substrate. Phys Rev Lett 2007;99:126805.

[35] Tedesco JT, Jernigan GG, Culbertson JC, Hite JK, Yang Y, Daniels KM, et al. Morphology characterization of argon-mediated epitaxial graphene on C-face SiC. Appl Phys Lett 2010;96:222103.

[36] Emtsev KV, Bostwick A, Horn K, Jobst J, Kellogg GL, Ley L, et al. Towards wafer-size graphene layers by atmospheric pressure graphitization of silicon carbide. Nat Mater 2009;8:203.

[37] Parga ALVd, Calleja F, Borca BMCG, Passeggi J, Hinarejos JJ, Guinea F, et al. Periodically rippled graphene: growth and spatially resolved electronic structure. Phys Rev Lett 2008;100:056807.

[38] Sutter PW, Flege J, Sutter EA. Epitaxial graphene on ruthenium. Nat Mater 2008;7:406.

[39] Wu J, Pisula W, Mullen K. Graphenes as potential material for electronics. Chem Rev 2007; 107:718.

[40] Yang X, Dou X, Rouhanipour A, Zhi L, Rader HJ, Mullen K. Two-dimensional graphene nanoribbons. J Am Chem Soc 2008;130:4216.

[41] Cai J, Ruffieux P, Jaafar R, Bieri M, Braun T, Blankenburg S, et al. Atomically precise bottomup fabrication of graphene nanoribbons. Nature 2010;466:470.

[42] Son Y-W, Cohen ML, Louie SG. Energy gaps in graphene nanoribbons. Phys Rev Lett 2006;97:216803.

[43] Barone V, Hod O, Scuseria GE. Electronic structure and stability of semiconducting graphene nanoribbons. Nano Lett 2006;6:2748.

[44] Areshkin DA, Gunlycke D, White CT. Ballistic transport in graphene nanostrips in the presence of disorder: importance of edge effects. Nano Lett 2007;7:204.

[45] Yan Q, Huang B, Yu J, Zheng F, Zang J, Wu J, et al. Intrinsic current-voltage characteristics of graphene nanoribbon transistors and effect of edge doping. Nano Lett 2007;7:1469.

[46] Han MY, Ozyilmaz B, Zhang Y, Kim P. Energy band-gap engineering of graphene nanoribbons. Phys Rev Lett 2007;98:206805.

[47] Jiao L, Zhang L, Wang X, Diankov G, Dai H. Narrow graphene nanoribbons from carbon 
nanotubes. Nature 2009;458:877.

[48] Shimizu T, Haruyama J, Marcano DC, Kosinkin DV, Tour JM, Hirose K, et al. Large intrinsic energy bandgaps in annealed nanotube-derived graphene nanoribbons. Nature Nanotechnol 2010;6:45.

[49] Kosynkin DV, Higginbotham AL, Sinitskii A, Lomeda JR, Dimiev A, Price BK, et al. Longitudinal unzipping of carbon nanotubes to form graphene nanoribbons. Nature 2009;458:872.

[50] Sinitskii A, Dimiev A, Kosynkin DV, Tour JM. Graphene nanoribbon devices produced by oxidative unzipping of carbon nanotubes. ACS Nano 2010;4:5405.

[51] Sinitski A, Dimiev A, Corley DA, Fursina AA, Kosynkin DV, Tour JM. Kinetics of diazonium functionalization of chemically converted graphene nanoribbons. ACS Nano 2010;4:1949.

[52] Elias AL, Botello-Mendez AR, Meneses-Rodriguez D, Gonzalez VJ, Ramirez-Gonzalez D, Ci $\mathrm{L}$, et al. Longitudinal cutting of pure and doped carbon nanotubes to form graphitic nanoribbons using metal clusters as nanoscalpels. Nano Lett 2010;10:366.

[53] Jiao L, Wang X, Diankow G, Wang H, Dai H. Facile synthesis of high-quality graphene nanoribbons. Nature Nanotechnol 2010;5:321.

[54] Xie L, Jiao L, Dai H. Selective etching of graphene edges by hydrogen plasma. J Am Chem Soc 2010;132:14751.

[55] Stankovich S, Dikin DA, Dommett GHB, Kohlhaas KM, Zimney EJ, Stach EA, et al. Graphenebased composite materials. Nature 2006;442:282.

[56] Schniepp HC, Li JL, McAllister MJ, Sai H, Herrera-Alonso M, Adamson DH, et al. Functionalized single graphene sheets derived from splitting graphite oxide. J Phys Chem B 2006;110:8535.

[57] Gomez-Navarro C, Weitz RT, Bittner AM, Scolari M, Mews A, Burghard M, et al. Electronic transport properties of individual chemically reduced graphene oxide sheets. Nano Lett 2007;7:3499.

[58] Virendra S, Daeha J, Lei Z, Soumen D, Saiful IK, Sudipta S. Graphene based materials: Past, present and future. Progress in Materials ScienceProgress in Materials Science 56 2011.1178:1271.

[59] Stankovich S, Piner RD, Chen XQ, Wu NQ, Nguyen ST, Ruoff RS. Stable aqueous dispersions of graphitic nanoplatelets via the reduction of exfoliated graphite oxide in the presence of poly(sodium 4-styrenesulfonate). J Mater Chem 2006;16:155.

[60] Athanasios B, Bourlinos DG, Dimitrios Petridis, Tamas Szabo, Anna Szeri, Imre Dekany. Graphite oxide: chemical reduction to graphite and surface modification with aliphatic amines and amino acids. Langmuir 2003;19:6050.

[61] Hummers WOR. Preparation of graphite oxide. J Am Chem Soc 1958;80:1339.

[62] Brodie, Sur le poids atomique du graphite. Ann. Chim. Phys.1860, 59, 466.

[63] Staudenmaier L, Ber. Deut. Verfahren zur Darstellung der Graphitsäure Chem. Ges.1898,31,1481.

[64] Yanwu Z, Shanthi M , Weiwei C, Xuesong L, Ji Won S , Jeffrey R. Potts and Rodney S. Ruoff. Graphene and Graphene Oxide: synthesis, properties and applications. Adv.Mater. 2010,22, 3906-3924. 
[65] Stankovich S, Dikin D.A, Piner RD, Kohlhaas K.A, Kleinhammes A, Jia Y, Wu Y, Nguyen ST, Ruoff RS. Synthesis of graphene-based nanosheets via chemical reduction of exfoliated graphite oxide. Carbon. 2007, 45, 1558.

[66] Eda G, Fanchini G, Chhowalla M. Large-area ultrathin films of reduced graphene oxide as a transparent and flexible electronic material. Nature Nanotechnol 2008;3:270.

[67] Lee C-G, Park S, Ruoff RS, Dodabalapur A. Integration of reduced graphene oxide into organic field-effect transistors as conducting electrodes and as a metal modification layer. Appl Phys Lett 2009;95:023304.

[68] Shin H-J, Kim KK, Benayad A, Yoon S-M, Park HK, Jung I-S, et al. Efficient reduction of graphite oxide by sodium borohydride and its effect on electrical conductance. Adv Funct Mater 2009;19:1987.

[69] Yongchao S and Edward T. Synthesis of Water Soluble Graphene. Nano Lett 2008, 8 (6),16791682.

[70] Guoxiu W, Juan Y, Jinsoo P, Xinglong G, Bei W, Hao L and Jane Y. Facile Synthesis and Characterization of Graphene Nanosheets. J. Phys. Chem. 2008,112, 8192.

[71] Dua V, Surwade SP, Ammu S, Agnihotra SR, Jain S, Roberts KE, Park S, Ruoff RS, Manohar SK. All-organic vapor sensor using inkjet-printed reduced graphene oxide. Chem. Int. Ed. $2010,122,2200$.

[72] McAllister MJ, Li J-L, Adamson DH, Schniepp HC, Abdala AA, Liu J, et al. Single sheet functionalized graphene by oxidation and thermal expansion of graphite. Chem Mater 2007; 19:4396.

[73] Dubin S, Gilje S, Wang K, Tung VC, Cha K, Hall AS, et al. A one-step, solvothermal reduction method for producing reduced graphene oxide dispersions in organic solvents. ACS Nano 2010;4:3845.

[74] Xu Y, Liu Z, Zhang X, Wang Y, Tian J, Huang Y, et al. A graphene hybrid material covalently functionalized with porphyrin:synthesis and optical limiting property. Adv Mater 2009;21:1275.

[75] Liu Z, Robinson JT, Sun X, Dai H. PEGylated nanographene oxide for delivery of waterinsoluble cancer drugs. J Am Chem Soc 2008;130:10876.

[76] Veca LM, Lu F, Meziani MJ, Cao L, Zhang P, Qi G, et al. Chem Commun 2009:2565.

[77] Bai H, Xu Y, Zhao L, Hou Y. Non-covalent functionalization of graphene sheets by sulfonated polyaniline. Chem Commun 2009:1667.

[78] Qi X, Pu K-Y, Zhou X, Li H, Liu B, Boey F, et al. Conjugated-polyelectrolyte-functionalized reduced graphene oxide with excellent solubility and stability in polar solvents. Small 2010;6:663.

[79] Geng J, Jung H-T. Porphyrin functionalized graphene sheets in aqueous suspensions: from the preparation of graphene sheets to highly conductive graphene films. J Phys Chem C 2010;114:8227.

[80] Yang Q, Pan X, Huang F, Li K. Fabrication of high-concentration and stable aqueous suspensions of graphene nanosheets by noncovalent functionalization with lignin and cellulose derivatives. J Phys Chem C 2010;114:3811.

[81] Kong B-S, Geng J, Jung H-T. Layer-by-layer assembly of graphene and gold nanoparticles by vacuum filtration and spontaneous reduction of gold ions. Chem Commun 2009:2174.

[82] Zhang L-S, Liang X-Q, Song W-G, Wu Z-Y. Identification of the nitrogen species on N-doped 
graphene layers and Pt/NG composite catalyst for direct methanol fuel cell. Phys Chem Chem Phys 2010;12:12055.

[83] Sundaram RS, Gómez-Navarro C, Balasubramanian K, Burghard M, Kern K. Electrochemical modification of graphene. Adv Mater 2008;20:3050.

[84] Paek S-M, Yoo E, Honma I. Enhanced cyclic performance and lithium storage capacity of SnO4 /graphene nanoporous electrodes with three-dimensionally delaminated flexible structure. Nano Lett 2008;9:72.

[85] Liang Y, Wang H, Sanchez Casalongue H, Chen Z, Dai H. TiO2 nanocrystals grown on graphene as advanced photocatalytic hybrid materials. Nano Res 2010;3:701.

[86] Zhou X, Huang X, Qi X, Wu S, Xue C, Boey FYC, et al. In situ synthesis of metal nanoparticles on single-layer graphene oxide and reduced graphene oxide surfaces. J Phys Chem C 2009;113:10842.

[87] Shen J, Hu Y, Shi M, Li N, Ma H, Ye M. One step synthesis of graphene oxide-magnetic nanoparticle composite. J PhysChem C 2010;114:1498.

[88] Wang D, Choi D, Li J, Yang Z, Nie Z, Kou R, et al. Self-assembled TiO2 graphene hybrid nanostructures for enhanced Li-ion insertion. ACS Nano 2009;3:907.

[89] Wang H, Cui L-F, Yang Y, Sanchez Casalongue H, Robinson JT, Liang Y, et al. Mn3O graphene hybrid as a high-capacity anode material for lithium ion batteries. J Am Chem Soc 2010;132:13978.

[90] Yang X, Zhang X, Ma Y, Huang Y, Wang Y, Chen Y. Superparamagnetic graphene oxideFe3O4 nanoparticles hybrid forcontrolled targeted drug carriers. J Mater Chem 2009;19:2710.

[91] Rafiee MA, Rafiee J, Srivastava I, Wang Z, Song H, Yu Z-Z, et al. Fracture and fatigue in graphene nanocomposites. Small 2010;6:179.

[92] Wang H, Robinson JT, Diankov G, Dai H. Nanocrystal growth on graphene with various degrees of oxidation. J Am Chem Soc 2010;132:3270.

[93] Cao A, Liu Z, Chu S, Wu M, Ye Z, Cai Z, et al. A facile one-step method to produce graphene$\mathrm{CdS}$ quantum dot nanocomposites as promising optoelectronic materials. Adv Mater 2010;22:103.

[94] Lin Y, Zhang K, Chen W, Liu Y, Geng Z, Zeng J, et al. Dramatically enhanced photoresponse of reduced graphene oxide with linker-free anchored CdSe nanoparticles. ACS Nano 2010;4:3033.

[95] Watcharotone S, Dikin DA, Stankovich S, Piner R, Jung I, Dommett GHB, et al. Graphenesilica composite thin films as transparent conductors. Nano Lett 2007;7:1888.

[96] Li B, Zhang X, Li X, Wang L, Han R, Liu B, et al. Photo-assisted preparation and patterning of large-area reduced graphene oxide-TiO2 conductive thin film. Chem Commun 2010;46:3499.

[97] Nair RR, Blake P, Grigorenko AN, Novoselov KS, Booth TJ, Stauber T, et al. Fine structure constant defines visual transparency of graphene. Science 2008;320:1308.

[98] Novoselov KS, Jiang D, Schedin F, Booth TJ, Khotkevich VV, Morozov SV, et al. Twodimensional atomic crystals. Proc Natl Acad Sci USA 2005;102:10451.

[99] Chen J-H, Jang C, Xiao S, Ishigami M, Fuhrer MS. Intrinsic and extrinsic performance limits of graphene devices on $\mathrm{SiO} 2$. Nat Nanotechnol 2008;3:206.

[100] Meyer JC, Geim AK, Katsnelson MI, Novoselov KS, Booth TJ, Roth S. The structure of 
suspended graphene sheets. Nature 2007;446:60.

[101] Hwang EH, Adam S, Das Sarma S. Carrier transport in two-dimensional graphene layers. Phys Rev Lett 2007;98:186806.

[102] Bolotin KI, Sikes KJ, Jiang Z, Klima M, Fudenberg G, Hone J, et al. Ultrahigh electron mobility in suspended graphene. Solid State Commun 2008;146:351.

[103] Geim AK, Novoselov KS. The rise of graphene. Nat Mater 2007;6:183.

[104] Chen Z, Lin Y-M, Rooks MJ, Avouris P. Graphene nano-ribbon electronics. Phys E: Lowdimen Syst Nanostruct 2007;40:228.

[105] Trauzettel B, Bulaev DV, Loss D, Burkard G. Spin qubits in graphene quantum dots. Nat Phys 2007;3:192.

[106] Nilsson J, Castro Neto AH, Guinea F, Peres NMR. Electronic properties of bilayer and multilayer graphene. Phys Rev B 2008;78:045405.

[107] Ohta T, Bostwick A, Seyller T, Horn K, Rotenberg E. Controlling the electronic structure of bilayer graphene. Science 2006;313:951.

[108] Evaldsson M, Zozoulenko IV, Xu H, Heinzel T. Edge-disorder-induced Anderson localization and conduction gap in graphene nanoribbons. Phys Rev B 2008;78:161407.

[109] Peng X, Ahuja R. Symmetry breaking induced bandgap in epitaxial graphene layers on SiC. Nano Lett 2008;8:4464.

[110] Kim S, Ihm J, Choi HJ, Son Y-W. Origin of anomalous electronic structures of epitaxial graphene on silicon carbide. Phys Rev Lett 2008;100:176802.

[111] De Heer WA, Berger C, Wu X, First PN, Conrad EH, Li X, et al. Epitaxial graphene. Solid State Commun 2007;143:92.

[112] Reina A, Jia X, Ho J, Nezich D, Son H, Bulovic V, et al. Large area, few-layer graphene films on arbitrary substrates by chemical vapor deposition. Nano Lett 2008;9:30.

[113] Kim KS, Zhao Y, Jang H, Lee SY, Kim JM, Kim KS, et al. Large-scale pattern growth of graphene films for stretchable transparent electrodes. Nature 2009;457:706.

[114] Novoselov KS, McCann E, Morozov SV, Fal'ko VI, Katsnelson MI, Zeitler U, et al. Unconventional quantum Hall effect and Berry's phase of 2 pi in bilayer graphene. Nat Phys 2006;2:177.

[115] Castro EV, Novoselov KS, Morozov SV, Peres NMR, dos Santos JMBL, Nilsson J, et al. Biased bilayer graphene:semiconductor with a gap tunable by the electric field effect. Phys Rev Lett 2007;99:216802.

[116] Gomez-Navarro C, Weitz RT, Bittner AM, Scolari M, Mews A, Burghard M, et al. Electronic transport properties of individual chemically reduced graphene oxide sheets. Nano Lett 2007;7:3499.

[117] Li D, Muller MB, Gilje S, Kaner RB, Wallace GG. Processable aqueous dispersions of graphene nanosheets. Nat Nanotechnol 2008;3:101.

[118] Shuai W, Priscilla K A, Ziqian W, Ai L Tang, John T. L and Kian P L. High Mobility, Printable, and Solution-Processed Graphene Electronics. Nano Lett; 2010, 10 (1), 92:98.

[119] Tsoukleri G, Parthenios J, Papagelis K, Jalil R, Ferrari AC, Geim AK, et al. Subjecting a graphene monolayer to tension and compression. Small 2009;5:2397. 
[120] Lee C, Wei XD, Li QY, Carpick R, Kysar JW, Hone J. Elastic and frictional properties of graphene. Phys Status Solidi B - Basic Solid State Phys 2009;246:2562.

[121] Ni ZH, Yu T, Lu YH, Wang YY, Feng YP, Shen ZX. Uniaxial strain on graphene: Raman spectroscopy study and band-gap opening. ACS Nano 2008;2:2301.

[122] Cristina G N, Marko B and Klaus K. Elastic Properties of Chemically Derived Single Graphene Sheets. Nano Lett. 8 (7), 2008. 2045:2049.

[123] Peng Z, Lulu Ma, Feifei F, Zhi Z, Cheng P, Phillip E. L, Zheng L, Yongji G, Jiangnan Z, Xingxiang Z, Pulickel M. A, Ting $Z$ and Jun L. Fracture toughness of graphene. Nature Communications, 5, 2014.

[124] Pop E, Mann D, Wang Q, Goodson K, Dai H. Thermal conductance of an individual single-wall carbon nanotube above room temperature. Nano Lett 2005;6:96.

[125] Kim P, Shi L, Majumdar A, McEuen PL. Thermal transport measurements of individual multiwalled nanotubes. Phys Rev Lett 2001;87:215502.

[126] Ghosh S, Calizo I, Teweldebrhan D, Pokatilov EP, Nika DL, Balandin AA, et al. Extremely high thermal conductivity of graphene: prospects for thermal management applications in nanoelectronic circuits. Appl Phys Lett 2008;92:151911.

[127] Seol JH, Jo I, Moore AL, Lindsay L, Aitken ZH, Pettes MT, et al. Two-dimensional phonon transport in supported graphene. Science 2010;328:213.

[128] Lee J, Yoon D, Kim, Lee S W, Cheong H. Thermal conductivity of suspended pristine graphene measured by Raman spectroscopy. Physical Review B. 83 8, 2011.

[129] Pettes M T, Jo I, Yao Z, Shi L. Influence of Polymeric Residue on the Thermal Conductivity of Suspended Bilayer Graphene. Nano Letters. 11 (3), 2011. 1195:1200.

[130] Wang Y, Shi Z, Huang Y, Ma Y, Wang C, Chen M, et al. Supercapacitor devices based on graphene materials. J Phys Chem C 2009;113:13103.

[131] Ivan K, Freddie W, Thomas HB, Dmitry KP, Caniam LB, Saverio R, Monica FC. Novel highly conductive and transparent graphene based conductors. Adv. Mater, 24, 2012, 2844:2849.

[132] Lahiri I, Oh S-W, Hwang JY, Cho S, Sun Y-K, Banerjee R, et al. High capacity and excellent stability of lithium ion battery anode using interface-controlled binder-free multiwall carbon nanotubes grown on copper. ACS Nano 2010;4:3440.

[133] Guo ZP, Zhao ZW, Liu HK, Dou SX. Electrochemical lithiation and de-lithiation of MWNTSn/SnNi nanocomposites. Carbon 2005;43:1392.

[134] Fu Y, Ma R, Shu Y, Cao Z, Ma X. Preparation and characterization of SnO2/carbon nanotube composite for lithium ion battery applications. Mater Lett 2009;63:1946.

[135] Dimov N, Kugino S, Yoshio M. Mixed silicon-graphite composites as anode material for lithium ion batteries: influence of preparation conditions on the properties of the material. $\mathrm{J}$ Power Sour 2004;136:108.

[136] Yoo E, Kim J, Hosono E, Zhou H-s, Kudo T, Honma I. Large reversible Li storage of graphene nanosheet families for use in rechargeable lithium ion batteries. Nano Lett 2008;8:2277.

[137] Pan D, Wang S, Zhao B, Wu M, Zhang H, Wang Y, et al. Li storage properties of disordered graphene nanosheets. Chem Mater 2009;21:3136.

[138] Yang S, Feng X, Ivanovici S, Müllen K. Fabrication of graphene-encapsulated oxide nanoparticles: towards highperformance anode materials for lithium storage. Angew Chem Int 
Ed 2010;49:8408.

[139] Wu Z-S, Ren W, Wen L, Gao L, Zhao J, Chen Z, et al. Graphene anchored with Co3O4 nanoparticles as anode of lithium ion batteries with enhanced reversible capacity and cyclic performance. ACS Nano 2010;4:3187.

[140] Larcher D, Beattie S, Morcrette M, Edstrom K, Jumas J-C, Tarascon J-M. Recent findings and prospects in the field of pure metals as negative electrodes for Li-ion batteries. J Mater Chem 2007; 17:3759.

[141] Zhou G, Wang D-W, Li F, Zhang L, Li N, Wu Z-S, et al. Graphene-wrapped Fe3O4 anode material with improved reversible capacity and cyclic stability for lithium ion batteries. Chem Mater 2010;22:5306.

[142] Xiaojun Z, Gang W, Yixuan Z, Hui W. Flexible free-standing ternary CoSnO3/graphene/carbon nanotubes composite papers as anodes for enhanced performance of lithium-ion batteries. Energy. 2017, 172:180.

[143] Seung K, Chae Y, Suyeon Y, Yuanzhe P, Porous Mn3O4 nanorod/reduced graphene oxide hybrid paper as a flexible and binder-free anode material for lithium ion battery. Energy. 2016, 266:273.

[144] Xia J, Chen F, Li J, Tao N. Measurement of the quantum capacitance of graphene. Nat Nanotechnol 2009;4:505.

[145] Zhu YW, Murali S, Stoller MD, Velamakanni A, Piner RD, Ruoff RS. Microwave assisted exfoliation and reduction of graphite oxide for ultracapacitors. Carbon 2010;48:2118.

[146] Wu Z-S, Wang D-W, Ren W, Zhao J, Zhou G, Li F, et al. Anchoring hydrous RuO2 on graphene sheets for high-performance electrochemical capacitors. Adv Funct Mater 2010;20:3595.

[147] Wu ZS, Ren WC, Wang DW, Li F, Liu BL, Cheng HM. High-energy MnO2 nanowire/graphene and graphene asymmetric electrochemical capacitors. ACS Nano 2010;4:5835.

[148] Kai W, Liwei L, Tiezhu Z, Zaifei L. Nitrogen-doped graphene for supercapacitor with longterm electrochemical stability. Energy, Volume 70, 2014, 612:617.

[149] Manoj KS, Shady A, Sadhan M, Jacques T. A novel configuration of electrical double layer capacitor with plastic crystal based gel polymer electrolyte and graphene nano-platelets as electrodes: A high rate performance. Energy, 80, 2015, 465:473.

[150] Yanping Y, Nan Z, Tianyu L, Xiaoling C, Weiyue L. Thermal performance enhancement of palmitic-stearic acid by adding graphene nanoplatelets and expanded graphite for thermal energy storage: A comparative study. Energy. 2016, 488:497.

[151] Mehrali M, Sara TL, Mehdi M, Teuku M, Indra M, Hendrik S. Preparation and properties of highly conductive palmitic acid/graphene oxide composites as thermal energy storage materials. Energy, 58, 2013, 628:634.

[152] Wenzhen L, Changhai L, Weijiang Z, Jieshan Q, Zhenhua Z, Gongquan S and Qin X. Preparation and Characterization of Multiwalled Carbon Nanotube-Supported Platinum for Cathode Catalysts of Direct Methanol Fuel Cells. J. Phys. Chem. B 2003,107,6292:6299.

[153] Gong K, Du F, Xia Z, Durstock M, Dai L. Nitrogen-doped carbon nanotube arrays with high electrocatalytic activity for oxygen reduction. Science 323.2009.760:764.

[154] Novoselov KS, Geim AK, Morozov SV, Jiang D, Zhang Y, Dubonos SV, Grigorieva IV, Firsov AA. Electric field effect in atomically thin carbon films. Science. 2004 Oct 
22;306(5696):666:669.

[155] Dikin DA, Stankovich S, Zimney EJ, Piner RD, Dommett GH, Evmenenko G, Nguyen ST, Ruoff RS Preparation and characterization of graphene oxide paper. Nature. 2007 Jul 26;448(7152):457:460.

[156] Kim KS, Zhao Y, Jang H, Lee SY, Kim JM, Kim KS, Ahn JH, Kim P, Choi JY, Hong BH. Large-scale pattern growth of graphene films for stretchable transparent electrodes. Nature. 2009 Feb 5;457(7230):706:810.

[157] Eun KC, InYup J, Seo YB, Hwa JL, Hyeon S, Liming D and Jong B, High-yield exfoliation of three-dimensional graphite into two-dimensional graphene-like sheets, Chemical Communications 46.2010.6320:6322.

[158] Wu ZS, Wang DW, Ren W, Zhao J, Zhou G. Anchoring hydrous RuO2 on graphene sheets for high-performance electrochemical capacitors Advanced Functional Materials 20 (20), 3595:3602.

[159] Hernández J, Solla-Gullón J, Herrero E. Gold nanoparticles synthesized in a water-in-oil microemulsion: electrochemical characterization and effect of the surface structure on the oxygen reduction reaction. Journal of Electroanalytical Chemistry. 574.2004.185:196.

[160] Yoo E, Okata T, Akita T, Kohyama M, Nakamura J, Honma I. Enhanced electrocatalytic activity of Pt subnanoclusters on graphene nanosheet surface. Nano Lett. 2009:9(6):2255:2259.

[161] SM Choi, MH Seo, HJ Kim, WB Kim. Synthesis of surface-functionalized graphene nanosheets with high Pt-loadings and their applications to methanol electro oxidation. Carbon 49 (3), 904:909.

[162] Rong K, Yuyan S, Donghai W, Mark HE, Ja HK, Jun W, Vilayanur V, Chongmin W, Yuehe L, Yong W, Ilhan A, Jun L. Enhanced activity and stability of Pt catalysts on functionalized graphene sheets for electrocatalytic oxygen reduction. Electrochemistry Communications 11 (2009) 954:957.

[163] Lee WH, Yanga HN, Parka HW, Choia BS, Yi SC, Synergistic effect of boron/nitrogen codoping into graphene and intercalation of carbon black for Pt-BCN-Gr/CB hybrid catalyst on cell performance of polymer electrolyte membrane fuel cell. ENergy 2016, 314:324.

[164] Yang HN, Lee DC, Park KW, Kim WJ. Platinum-boron doped graphene intercalated by carbon black for cathode catalyst in proton exchange membrane fuel cell. energy. 2015, 500:510.

[165] Jing-Yi J, Yu-Wei H, Chun-Han H, Hsisheng T, Daniel K, Ping-Lin K, Three-dimensional network of graphene grown with carbon nanotubes as carbon support for fuel cells. Energy, 53, 2013, 282:287.

[166] Bae S, Kim H, Lee Y, Xu X, Park J, Zheng Y, Balakrishnan J, Lei T, Kim HR, Song YI. Rollto-roll production of 30-inch graphene films for transparent electrodes. Nature Nanotechnology, $5,2010,574: 578$.

[167] Kim KK, Reina A, Shi Y, Park H, Li LJ, Lee YH, Kong J. Enhancing the conductivity of transparent graphene films via doping. Nanotechnology, 21, 2010.

[168] Sajid A, Adnan I, Sayeed ZS, Benjamin B, Muhammad SK. On using graphene based conductors as transmission for feed networks in printed antenna arrays. IEEE International Conference on Electro/Information Technology (EIT), 2015, 681:683.

[169] Wang L, Liu W, Zhang Y, Zhang ZH, Tan ST, Yi X. Graphene-based transparent conductive electrodes for GaN-based light emitting diodes: Challenges and countermeasures. Nano Energy, $12,2015,419: 436$. 
[170] Youngbin L, Jong HA. Graphene based transparent conductive films. Nano brief reports and reviews, 8, 2013. 1:16.

[171] Shin SE, Choi HJ, Shin JH, Bae DH. Strengthening behavior of few-layered graphene/aluminum composites. Carbon 2015;82:143e51.

[172]Rashad M, Pan F, Tang A, Asif M. Effect of Graphene Nanoplatelets addition on mechanical properties of pure aluminum using a semi-powder method. Prog Nat Sci Mater Int 2014;24:101e8.

[173] Wang J, Li Z, Fan G, Pan H, Chen Z, Zhang D. Reinforcement with graphene nanosheets in aluminum matrix composites. Scr Mater 2012;66:594e7.

[174] Li Z, Fan G, Tan Z, Guo Q, Xiong D, Su Y, et al. Uniform dispersion of graphene oxide in aluminum powder by direct electrostatic adsorption for fabrication of graphene/aluminum composites. Nanotechnology 2014;25:325601.

[175] Liu J, Khan U, Coleman J, Fernandez B, Rodriguez P, Naher S, et al. Graphene oxide and graphene nanosheet reinforced aluminium matrix composites: powder synthesis and prepared composite characteristics. Mater Des 2016;94:87e94.

[176] Liu J, Fernandez B, Rodriguez P, Naher S, Brabazon D. Powder processing methodology for production of graphene oxide reinforced aluminium matrix composites. Adv Mater Process Technol 2016;2. http://dx.doi.org/10.1080/ 2374068X.2016.1244389. 